\title{
The effect of ENSO-induced rainfall and circulation changes on the direct and indirect radiative forcing from Indonesian biomass-burning aerosols
}

\author{
A. Chrastansky ${ }^{1,2}$ and L. D. Rotstayn ${ }^{1,2}$ \\ ${ }^{1}$ CSIRO Marine and Atmospheric Research, Private Bag 1, Aspendale 3195, Victoria, Australia \\ ${ }^{2}$ The Centre for Australian Weather and Climate Research. A partnership between CSIRO and the Bureau of Meteorology \\ Correspondence to: A. Chrastansky (alena.chrastansky@csiro.au)
}

Received: 10 January 2012 - Published in Atmos. Chem. Phys. Discuss.: 17 February 2012

Revised: 27 July 2012 - Accepted: 27 November 2012 - Published: 3 December 2012

\begin{abstract}
Emissions of biomass-burning aerosols from the Indonesian region are known to vary in response to rainfall anomalies associated with the El Niño Southern Oscillation (ENSO). For the severe El Niño-related drought in 1997, there have been several attempts to estimate the direct radiative forcing from increased aerosol emissions over Indonesia, as well as the associated feedbacks on climate. However, these estimates have not considered indirect aerosol effects. Another question that has not been addressed is whether the effect of ENSO-related circulation and rainfall anomalies on radiative forcing is significant relative to the effect of changes in emissions. In this study, we analyse the direct and first indirect radiative forcing from $\mathrm{El} \mathrm{Niño-related} \mathrm{increased} \mathrm{emis-}$ sions of Indonesian biomass-burning aerosols, with and without the influence of ENSO-related rainfall and circulation anomalies.

We compare two experiments that are performed with the CSIRO-Mk3.6 atmospheric global climate model (GCM). The first experiment (AMIP) consists of a pair of runs that respectively represent El Niño and La Niña conditions. In these runs, the distribution of aerosols is simulated under the influence of realistic Indonesian biomass-burning aerosol emissions and sea surface temperatures (SSTs) for 1997 (El Niño) and 2000 (La Niña). The second experiment (CLIM) is identical to AMIP, but is forced by climatological SSTs, so that in CLIM meteorological differences between 1997 and 2000 are suppressed.

The comparison of AMIP and CLIM shows that the aerosol radiative forcing anomalies associated with ENSO (El Niño minus La Niña) are substantially stronger when
\end{abstract}

ENSO-related SST anomalies are taken into account. For the first indirect effect, the influence of SST-induced changes in rainfall and circulation exceeds that of changes in emissions. For the direct aerosol forcing, the influence of changes in SSTs and emissions are of comparable magnitude. Averaged over the Indonesian region $\left(5.6^{\circ} \mathrm{N}-11.2^{\circ} \mathrm{S}, 96.6^{\circ} \mathrm{E}-\right.$ $150.9^{\circ} \mathrm{E}$ ), the first indirect forcing is $-0.7 \mathrm{Wm}^{-2}$ in CLIM and $-2.2 \mathrm{Wm}^{-2}$ in AMIP during the months July to November. The direct aerosol forcing at the top of the atmosphere (surface) is $-1.0(-5.3) \mathrm{Wm}^{-2}$ in CLIM and -1.8 $(-9.1) \mathrm{Wm}^{-2}$ in AMIP during the same period.

Our results suggest that (a) the indirect aerosol effect from biomass-burning aerosols is strong enough to play an important role for impact assessments, and (b) that impacts of biomass-burning aerosols would be considerably underestimated if feedbacks of ENSO-related SST variations on radiative forcing are not taken into account.

\section{Introduction}

In the Indonesian region, high fire activity occurs in response to negative precipitation anomalies. These usually occur during the El Niño phase of the El Niño Southern Oscillation (ENSO). During the La Niña phase, fire activity is suppressed due to increased rainfall. Several studies have shown that enhanced emissions of biomass burning (BB) aerosols during El Niño exert substantial effects on regional radiative forcing (Duncan et al., 2003; Davison et al., 2004; Rajeev et al., 2008). 
ENSO has a large influence on the climate of the Indonesian region. These quasi-periodic variations of sea surface temperature (SST) in the equatorial Pacific change regional atmospheric dynamics. During El Niño events, warm SST anomalies prevail in the central Pacific, while SSTs around Indonesia are cooler than normal. During La Niña the situation is reversed, with cool SST anomalies in the central Pacific and warm SST anomalies around Indonesia. This causes a shift of the Walker circulation, so that the Indonesian region experiences increased rainfall in La Niña conditions and decreased precipitation rates during El Niño events. The ENSO-related reduction in rainfall can cause severe droughts in the Indonesian region during Indonesia's dry season (Hendon, 2003; Wooster et al., 2012).

Drier conditions in Indonesia are welcome for farmers and landowners with respect to land clearing. Fires are a common tool for land clearing in this region and are often deliberately set in the dry season (Murdiyarso and Adiningsih, 2007). During extended droughts the high risk of a fire spreading increases and fires sometimes end up raging for several months. In such cases, large amounts of trace gases and aerosols are emitted. In 1997, for example, one of the strongest El Niño events of the past century occurred. This caused severe droughts in the Indonesian region, which considerably promoted fire activity. A strong Indian Ocean Dipole coincided with the 1997 El Niño, which might have also contributed to the very dry conditions in Indonesia (Saji et al., 1999; Webster et al., 1999). As a result, intense fires occurred predominantly in the main islands of Indonesia, such as Sumatra and Borneo (Duncan et al., 2003; Liew et al., 1998), leading to exceptionally high aerosol loads in the Indonesian region (Levine, 1999; Parameswaran et al., 2004; van der Werf et al., 2010). Page et al. (2002), for instance, estimated that during the $1997 \mathrm{El} \mathrm{Niño} \mathrm{event} \mathrm{between} 0.8$ and $2.6 \mathrm{Pg}$ of carbon was released from fires in Indonesian peatlands. Van der Werf (2010) gave an estimate of $1.1 \mathrm{Pg} \mathrm{C}$ for equatorial Asia during the same event. Due to the anomalous easterly winds associated with El Niño, a large aerosol plume formed over the tropical Indian Ocean (Parameswaran et al., 2004).

Aerosols influence the regional radiation budget directly through scattering and absorption of short-wave (SW) radiation, and indirectly through their ability to change cloud properties by acting as cloud condensation nuclei ( $\mathrm{Ra}-$ manathan, 2001). Assuming that the liquid water content in a cloud remains unchanged and that water tends to distribute equally over the number of cloud droplets, an increase in the number of cloud droplets would result in smaller droplet radii. This increases cloud albedo and more solar radiation is reflected back to space (Twomey, 1974). Increased cloud albedo also results in a reduction of available solar radiation at the surface. Aerosol impacts on radiation can trigger changes in circulation and rainfall patterns (Rotstayn et al., 2007).
Beside the cloud-albedo effect, which is also referred to as the first indirect effect, there is a second indirect effect; the decreasing radius of cloud droplets tends to lower the precipitation efficiency (Albrecht, 1989). Langmann (2007) and Graf et al. (2009) showed that smoke released during the 1997 Indonesian fires caused a temporal and spatial redistribution of rainfall, so that rainfall appeared suppressed in some regions while increased in others. In areas with suppressed rainfall, remaining moisture led to the development of higher convective clouds. This is in agreement with other studies demonstrating a possible change in cloud thickness due to aerosol pollution (Pincus and Baker, 1994; Wood, 2007). The second indirect effect is highly uncertain in the global mean, even regarding its sign, (Lohmann and Feichter, 2005) and is not well resolved in global climate models (GCMs). This may be worse in highly convective regions with a complex geographical structure such as the Indonesian archipelago (Neale and Slingo, 2003; Menon and Rotstayn, 2006).

Several authors have estimated the direct radiative forcing due to aerosols associated with the 1997 Indonesian fires. These studies included model calculations (Davison et al., 2004; Duncan et al., 2003; Tosca et al., 2010) and satellite-based approaches (Podgorny et al., 2003; Rajeev et al., 2008). Indirect aerosol effects, however, have not been considered.

Duncan et al. (2003) used a tropospheric chemistry and transport model to estimate the impacts of trace gas and aerosol emissions on tropospheric chemistry. Their study showed that for the months September to November fireemitted aerosols in 1997 significantly perturbed the tropical radiative budget. Over the burning regions, the top of atmosphere (TOA) forcing was about $-10 \mathrm{Wm}^{-2}$ and close to zero in most other regions as organic and black carbon exerted forcings of opposite sign. The radiative impact was much stronger at the surface; over large areas of the Indian Ocean they estimated radiative forcing of about $-10 \mathrm{Wm}^{-2}$ and values as low as $-150 \mathrm{Wm}^{-2}$ over the burning regions. Their results also suggested that the reduction of insolation was partly responsible for a $20 \%$-decrease in the concentration of the hydroxyl radical over much of the Indian Ocean, an oxidant involved in the formation of sulphate aerosols.

Another calculation of the direct radiative forcing associated with the 1997 Indonesian fires was performed by Davison et al. (2004). They simulated the distribution of fireemitted aerosols during the months August to November 1997 using a GCM, not allowing for aerosol-feedbacks on the atmosphere. They found that the monthly-mean TOA radiative forcing reached its maximum in September with values of $-46 \mathrm{Wm}^{-2}$ in grid-boxes close to the emission regions. The TOA radiative forcing over the surrounding ocean was typically between -10 and $-25 \mathrm{Wm}^{-2}$. At the surface they found a maximum monthly mean reduction of insolation in September of about $200 \mathrm{Wm}^{-2}$ in some grid boxes, while otherwise their results were close to but somewhat larger than 
the radiative forcing estimates from Duncan et al. (2003). In two additional experiments Davison et al. (2004) showed that hydration of the smoke particles and feedbacks of aerosols on the climate increased the simulated radiative forcing magnitudes by $50 \%$ and $19 \%$, respectively.

Tosca et al. (2010) used a slightly different approach for assessing the radiative and climatic effects of aerosols associated with the 1997 fires. Using an atmospheric GCM coupled to a slab ocean model, they simulated the spread of the fire emissions in 1997 and compared the results to a La Niña year (2000) with low fire activity. Based on the difference between the high and low fire simulation, they showed that incoming SW radiation over a region encompassing Sumatra and Borneo was reduced by around $19 \mathrm{Wm}^{-2}$ at the surface during the months August to October, with a largest regional average occurring in September $\left(-25 \mathrm{Wm}^{-2}\right)$. Simultaneously, absorbing components led to atmospheric heating of $21 \mathrm{Wm}^{-2}$. They showed in their simulations that the radiative effects of aerosols cooled surface temperatures by about 0.4 to $0.5^{\circ} \mathrm{C}$. SST cooling in combination with atmospheric heating reduced precipitation by $0.9 \pm 0.6 \mathrm{~mm} \mathrm{~d}^{-1}$, which suggests a positive feedback loop between BB aerosols and drought stress in Indonesia. The authors noted that large scale ENSO-related changes were not represented in the boundary conditions, which were all climatological except for the fireinduced aerosol emissions.

Observational evidence for a radiative impact of Indonesian biomass burning aerosols was provided by Podgorny et al. (2003). Using satellite-derived observations of aerosol optical depths and measurements of single scattering albedo in combination with a radiation model, they concluded that during September to November the radiation absorbed by the Indian Ocean was reduced by 30 to $60 \mathrm{Wm}^{-2}$, while radiative forcing at the TOA was between 5 and $15 \mathrm{Wm}^{-2}$ under cloudy skies. This suggested atmospheric heating in the lower troposphere with heating rates of 0.6 to $1 \mathrm{~K} \mathrm{day}^{-1}$.

A similar approach was used by Rajeev et al. (2008). In their study they established a link between cool SST anomalies in the eastern Equatorial Indian Ocean and a reduction in SW radiation over a vast region over the Indian Ocean. They found that during September to October SW radiation was reduced by more than $46 \mathrm{Wm}^{-2}$, which led to an observed reduction in SSTs by 1 to $2{ }^{\circ} \mathrm{C}$. The authors suggested that there was a positive feedback of aerosol-induced cooling on the intensity of the prevailing Indian Ocean Dipole.

Another potential positive feedback involves the effects of ENSO-related precipitation and circulation anomalies on BB aerosols. Heil et al. (2007) demonstrated in an air quality study that reduced wet scavenging and increased westward aerosol transport substantially increased the intensity and spatial scale of aerosol pollution from the 1997 fires. In principle, larger aerosol burdens are expected to intensify radiative forcing. Hence, estimates of aerosol feedbacks in which aerosol-induced perturbations of SSTs are calculated against a background of climatological conditions (Tosca et al., 2010) may be underestimated. Similarly, it is common practice to calculate radiative forcing in GCMs using climatological SSTs (Lohmann et al., 2010; Taylor et al., 2012). To our knowledge, however, there has been no attempt to analyse the extent to which radiative forcing is changed by ENSO-related SST (and hence rainfall and circulation) anomalies.

In the present study, we quantify the impact of ENSOrelated SST anomalies on the magnitude and spatial extent of the radiative impact of Indonesian BB aerosols, addressing not only the direct but also (for the first time) the first indirect aerosol effect. We do not attempt to quantify the second indirect effect because, as discussed above, this would be highly speculative. In contrast to regional studies analysing Indonesian BB events from an air-quality perspective (Heil et al., 2007; Keywood et al., 2003), our study focuses on radiative forcing over a larger domain, and uses an atmospheric GCM for this purpose. We performed two experiments in which radiative perturbations caused by Indonesian BB aerosols are determined with and without the influence of ENSO-related meteorological changes forced by SST anomalies. This is done for the direct and the first indirect effect individually. We do not attempt to simulate feedbacks of BB aerosols on circulation; this would require further experiments in which the atmospheric GCM is coupled to an ocean model (Tosca et al., 2010).

The current study demonstrates that both the direct and first indirect radiative effect are substantially enhanced when the impacts of ENSO-related SSTs on climatic conditions are taken into account. This highlights the need to consider changes in meteorological conditions for realistically estimating radiative forcing and associated climatic impacts from intense biomass burning in ENSO-influenced regions.

\section{Method}

Two experiments were performed using the CSIRO Mark 3.6 (Mk3.6) atmospheric global climate model (GCM). The model is described in Sect. 2.1. Details of the experimental design are in Sect. 2.2.

\subsection{Model description}

The Mk3.6 GCM has a horizontal resolution of $1.9^{\circ} \times 1.9^{\circ}$ (spectral T63) and 18 vertical levels in the atmosphere. It is developed from the Mk3.5 model, which was described in detail by Gordon et al. (2010). The main differences between Mk3.5 and Mk3.6 are an interactive aerosol treatment and an updated radiation scheme in the latter version (Rotstayn et al., 2012). Here we summarise the aerosol-related aspects of the model.

The aerosol scheme of Mk3.6 includes eleven prognostic variables, namely the mass mixing ratios of dimethyl sulphide (DMS), sulphur dioxide $\left(\mathrm{SO}_{2}\right)$, sulphate $\left(\mathrm{SO}_{4}\right)$, 
hydrophobic and hydrophilic forms of black carbon (BC) and organic carbon (OC), as well as four size bins of mineral dust (radii ranging from $0.1-1,1-2,2-3$ and 3-6 $\mu \mathrm{m}$ ). Sea salt (film-drop and jet-drop) is diagnosed as a function of the $10 \mathrm{~m}$-wind speed above the ocean surface (O'Dowd et al., 1997) but is not treated prognostically. Information about the aerosol size distributions and hygroscopic growth can be found in Rotstayn et al. (2007) (their Table 2).

Global emissions of anthropogenic and $\mathrm{BB}$ aerosols and their precursors (i.e. carbonaceous aerosols and $\mathrm{SO}_{2}$ ) are prescribed and taken from the Coupled Model Intercomparison Project Phase 5 (CMIP5) (Lamarque et al., 2010). BB emissions from the Indonesian region $\left(5.6^{\circ} \mathrm{N}-11.2^{\circ} \mathrm{S}, 96.6^{\circ} \mathrm{E}-\right.$ $\left.150.9^{\circ} \mathrm{E}\right)$ are taken from the Global Fire Emission Database version 3 (GFED3) (van der Werf et al., 2010). Note that yields of secondary organic aerosols due to gas-to-particle conversion are not included in GFED3 emission estimates. For our experiments we used monthly-mean values of aerosol emissions; thus, the model does not resolve variability due to emission changes on shorter time scales. Depending on the climatic zone, BB emissions are injected into model layers following the emission height distributions in Dentener et al. (2006). In the tropics, for instance, $20 \%$ of the BB emissions are emitted in the lowest model layer to an altitude of $100 \mathrm{~m}$, and the remaining $80 \%$ are evenly distributed in higher levels up to $1000 \mathrm{~m}$.

The treatment of sulphur chemistry is based on that in ECHAM4 (Feichter et al., 1996) with some modifications as in Rotstayn and Lohmann (2002). It treats oxidation of sulphate precursors using prescribed, monthly-mean values of hydroxyl radical $\left(\mathrm{OH}^{-}\right)$, ozone $\left(\mathrm{O}_{3}\right)$, hydrogen peroxide $\left(\mathrm{H}_{2} \mathrm{O}_{2}\right)$ and nitrate radical $\left(\mathrm{NO}_{3}^{-}\right)$representative for the modern-day climate (see Feichter et al. (1996) and references herein). DMS and $\mathrm{SO}_{2}$ are both oxidized by reaction with $\mathrm{OH}^{-}$during the day (not at night); a diurnally averaged concentration of $\mathrm{OH}^{-}$is applied during the daylight hours. This approach leads to some simplifications in the sulphur cycle (e.g. ignoring the depletion of $\mathrm{H}_{2} \mathrm{O}_{2}$ ); however, for this study uncertainties in the carbonaceous aerosol treatment are likely to be more important. For carbonaceous aerosols (BC and $\mathrm{OC})$, the decay from their hydrophobic forms into their hydrophilic forms follows the simple approach of Cooke et al. (1999), assuming an e-folding decay-time of one day for the conversion. Particles containing black and organic carbon are assumed to exist as an internal mixture. All others are assumed to form externally mixed aerosols.

Prognostic aerosol species are transported by advection and sub-grid turbulent and convective mixing. Vertical advection is handled using a flux-corrected transport scheme (Van Leer, 1977), and horizontal advection follows a semiLagrangian scheme (McGregor, 1993). Parametrization of vertical turbulent mixing is based on the Louis (1979) stability-dependent mixing scheme. An additional non-local counter-gradient flux (Holtslag and Boville, 1993) is added when convective conditions occur. Vertical transport is based on the updraft mass flux and compensating subsidence from the convection scheme (Gregory and Rowntree, 1990).

Aerosols are removed from the atmosphere by wet and dry deposition. In-cloud and below-cloud wet-scavenging of aerosols are linked to precipitation processes in the stratiform-cloud microphysical scheme (Rotstayn, 1997; Rotstayn and Lohmann, 2002) and the convection scheme (Gregory and Rowntree, 1990). Dry deposition processes are based on Lohmann et al. (1999) for $\mathrm{SO}_{4}, \mathrm{SO}_{2}$ and carbonaceous aerosols. For dust, dry deposition and gravitational settling follows the formulation of Ginoux et al. (2001). Gravitational settling of carbonaceous aerosols and sulphate is ignored.

The radiation scheme treats direct and indirect aerosol radiative effects and includes SW effects from all aerosols as well as long wave effects of dust and volcanic aerosol (Rotstayn et al., 2007, 2011). Volcanic aerosols were set to zero for the purpose of this study. The first indirect aerosol effect is included in the cloud scheme of Mk3.6. Based on the num-

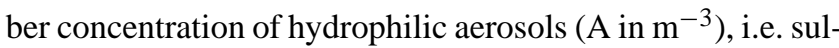
fate, sea salt and hydrophilic carbonaceous aerosol, the cloud droplet number concentration of liquid-water clouds $\left(N_{\mathrm{d}}\right.$ in $\mathrm{m}^{-3}$ ) is determined as follows (Jones et al., 1994):

$N_{\mathrm{d}}=\max \left\{375 \times 10^{6}\left(1-e^{-2.5 \times 10^{-9} \mathrm{~A}}\right), N_{\mathrm{d}_{\text {min }}}\right\}$,

where $\mathrm{N}_{\mathrm{d}_{\text {min }}}=10 \times 10^{6} \mathrm{~m}^{-3}$. Further details can be found in Rotstayn et al. (2012).

The cloud effective radius $\left(R_{\mathrm{e}}\right.$ in $\left.\mathrm{m}\right)$ is dependent on $\mathrm{N}_{\mathrm{d}}$

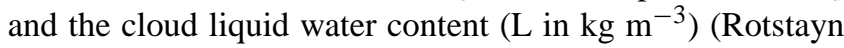
and Liu, 2003):

$\mathrm{R}_{\mathrm{e}}=\beta\left(\frac{3 \mathrm{~L}}{4 \pi \rho_{\mathrm{l}} \mathrm{N}_{\mathrm{d}}}\right)^{\frac{1}{3}}$

where $\rho_{1}$ is the density of liquid water and $\beta$ the spectral shape factor. The parametrization of $\beta$ follows an empirical relationship from Liu et al. (2008), accounting for variations in $\mathrm{L}$ and $\mathrm{N}_{\mathrm{d}}\left(\beta=0.07 \times\left(\mathrm{L} / \mathrm{N}_{\mathrm{d}}\right)^{-0.14}\right)$ (Rotstayn et al., 2009).

We suppressed the second indirect aerosol effect by setting $\mathrm{N}_{\mathrm{d}}$ to a constant value $\left(100 \times 10^{6} \mathrm{~m}^{-3}\right)$ in the rain-formation parameterization in the stratiform cloud scheme (Rotstayn and Liu, 2005). The convection scheme (Gregory and Rowntree, 1990) only includes very simple microphysics, and convective rain formation is unaffected by aerosols.

\subsection{Experimental design}

We performed two pairs of runs, each pair consisting of an El Niño and a La Niña simulation. In order to isolate radiative impacts of Indonesian BB aerosols, state-of-the-art estimates of BB emissions (based on GFED3) are used in the Indonesian region $\left(5.6^{\circ} \mathrm{N}-11.2^{\circ} \mathrm{S}, 96.6^{\circ} \mathrm{E}-150.9^{\circ} \mathrm{E}\right)$. In the El Niño simulations BB emissions from the Indonesian region are set to the year 1997 and for the La Niña simulations 
Table 1. Key characteristics of the experiments CLIM and AMIP.

\begin{tabular}{l|cc|cc}
\hline \multirow{2}{*}{ Experiment } & \multicolumn{2}{|c|}{ Indonesian BB Emissions } & \multicolumn{2}{|c}{ Global SST fields } \\
& El Niño & La Niña & El Niño & La Niña \\
\hline CLIM & 1997 & 2000 & \multicolumn{2}{|c}{ climatological } \\
AMIP & 1997 & 2000 & 1997 & 2000 \\
\hline
\end{tabular}

to the year 2000. For all other aerosol emissions (including $\mathrm{BB}$ emissions from regions other than Indonesia) both runs use year-2000 emissions from CMIP5. The BB emission estimate from CMIP5 for the year 2000 is representative for the decade 1997 to 2006 and deliberately does not try to resolve events such as El Niño (Lamarque et al., 2010).

For the first pair of runs (hereafter "CLIM") climatological SSTs are used. Hence, SST forcing is identical in the El Niño and La Niña runs of CLIM. For the second pair of runs (hereafter "AMIP") we use realistic SSTs for the year 1997 in the El Niño simulation and SSTs for the year 2000 in the La Niña simulation. The SST fields for the AMIP runs are taken from the Atmospheric Model Intercomparison Project (Hurrell et al., 2008).

A short summary of the most important characteristics of CLIM and AMIP is provided in Table 1.

In each experiment, we refer to the difference between the El Niño and the La Niña simulation as the forcing anomaly. In CLIM the meteorology is identical in all of the El Niño and La Niña simulations, so forcing anomalies are solely a result of ENSO-related variations in Indonesian BB emissions. In AMIP, the meteorology in the El Niño simulations differs from that in the La Niña simulations due to the SST forcing. Hence, in AMIP aerosol burdens are affected by ENSOrelated circulation and rainfall anomalies as well as changes in emissions. Note that we used an approach that ensures the meteorology is unaffected by radiative effects of aerosols, so that in CLIM the El Niño and La Niña simulations evolve with identical circulations; see appendix for details.

Double calls to the SW radiation scheme were used to calculate the direct and first indirect effects as instantaneous forcings (Lohmann et al., 2010). Each simulation was repeated with a slightly different treatment of the double call to the SW radiation scheme, to enable calculation of the direct and indirect effects individually; details are given in the appendix.

For the CLIM simulation we ran the model for $11 \mathrm{yr}$, including a model spin-up time of one year. Except for the BB emissions from the Indonesian region, El Niño and La Niña runs were initialised with identical conditions. For the analysis we averaged over the ten years after the spin-up phase. For AMIP, we chose a longer spin-up time of $10 \mathrm{yr}$ (19871996) to let soil moisture adjust to initial conditions, and used CMIP5 anthropogenic and BB aerosol emissions (Lamarque et al., 2010) from the year 2000 globally. From 1997 onwards the Indonesian aerosol emissions as well as global SST fields
GFED3 emission anomaly (Jul-Nov)

a) Sulphur Dioxide $\left(\mathrm{SO}_{2}\right)$

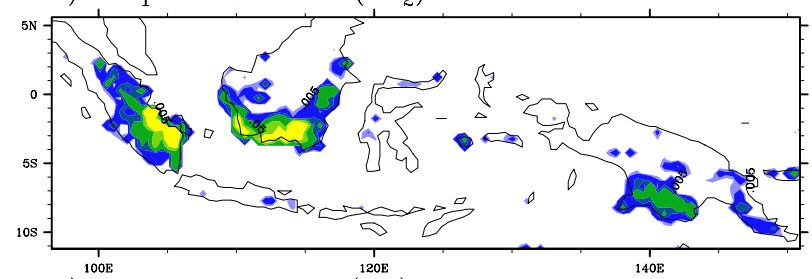

b) Organic Carbon $(\mathrm{OOC})$

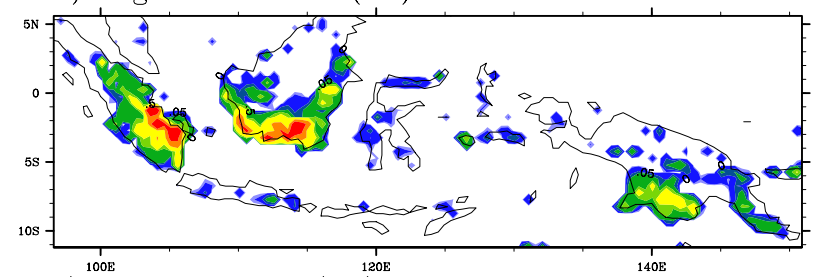

c) $\stackrel{100 \mathrm{E}}{\text { Black }}$ Carbon $(\mathrm{BC})$

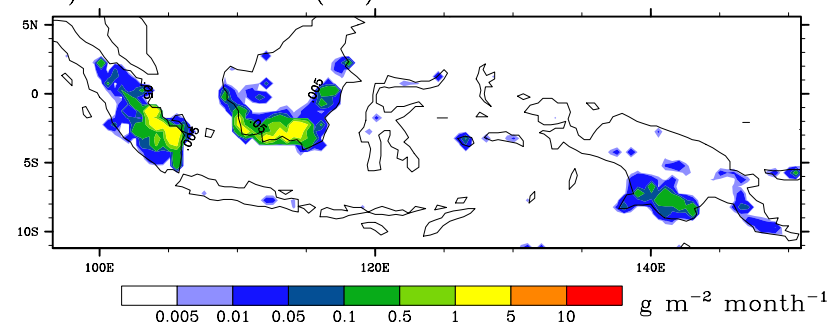

Fig. 1. Average July to November emission anomaly (1997 minus 2000) of (a) sulphur dioxide $\left(\mathrm{SO}_{2}\right)$, (b) organic carbon (OC) and (c) black carbon (BC) from the GFED3 database. Units are in gram of the substance per $\mathrm{m}^{2}$ per month. The area plotted is referred to in the text as the Indonesian region $\left(5.6^{\circ} \mathrm{N}-11.2^{\circ} \mathrm{S}, 96.6^{\circ} \mathrm{E}-150.9^{\circ} \mathrm{E}\right)$.

correspond to the years 1997 to 2006 . We carried out five AMIP simulations, each initialised from a different atmospheric state in 1987, so the results presented for 1997 and 2000 each represent five-member ensemble averages. The simulated period in AMIP was extended to 2006 so that the model behaviour could be compared with satellite retrievals using averaged values over the El Niño events in 2002, 2004 and 2006 and the La Niña events in 2000, 2001 and 2005, respectively. Values based on the extended (post-2000) AMIP runs will be referred to as "AMIP*".

\section{Results and Discussion}

\subsection{Aerosol emissions and burdens}

The amounts of the precursor gas $\mathrm{SO}_{2}$ and carbonaceous aerosols (OC and $\mathrm{BC}$ ) that were emitted from Indonesian fires in the El Niño year 1997 and the La Niña year 2000 differ substantially. While during the first half of the year emissions were similar in 1997 and 2000, emissions were much larger in 1997 during the months July to November. Table 2 summarizes annual and July-November averages of $\mathrm{SO}_{2}, \mathrm{OC}$ and $\mathrm{BC}$ emissions from the $\mathrm{El} \mathrm{Niña}$ and 

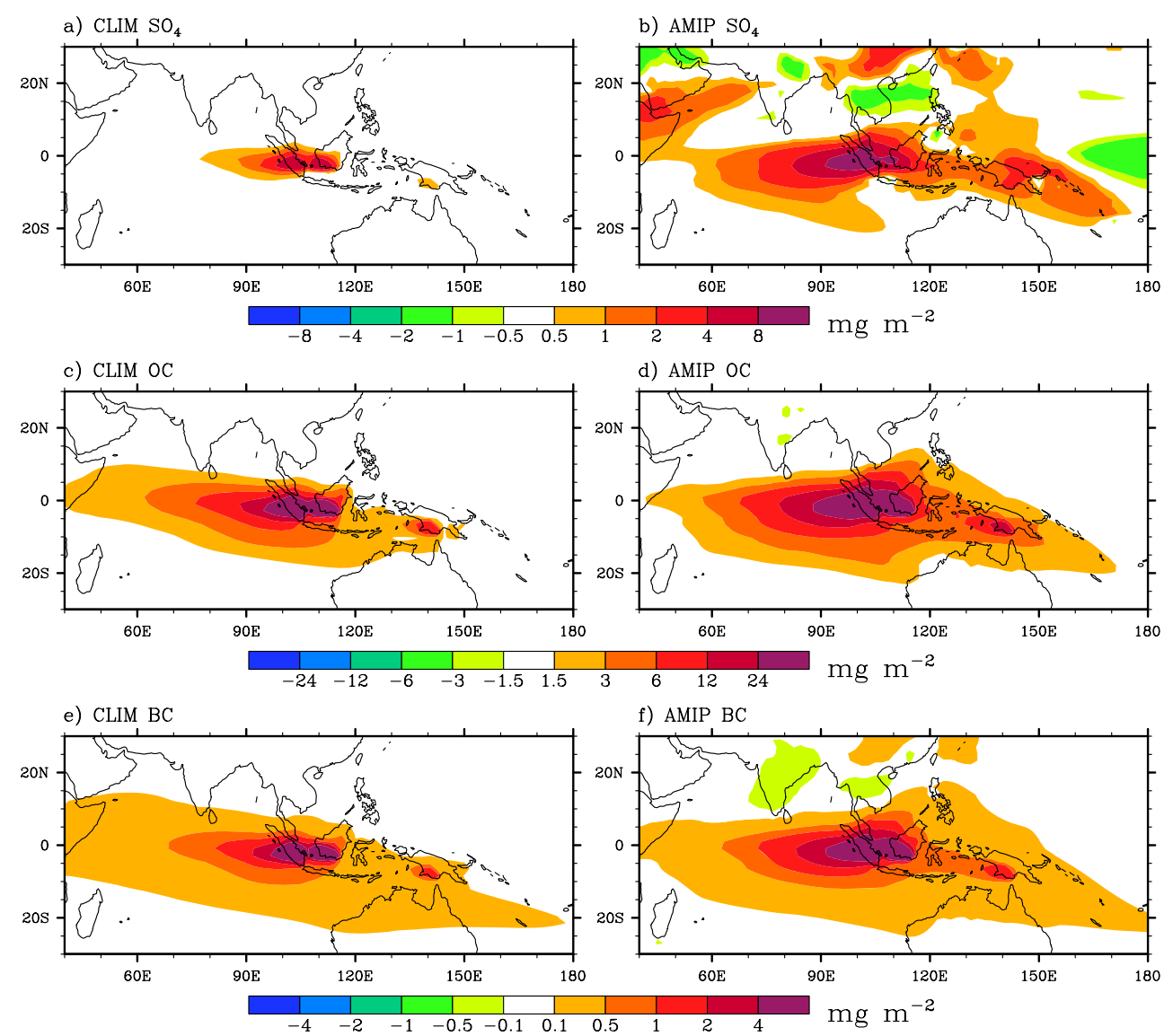

Fig. 2. July to November average of the sulphate $\left(\mathrm{SO}_{4}\right)$, organic carbon $(\mathrm{OC})$ and black carbon (BC) burden anomalies (El Niño minus La Niño) from the CLIM (left column) and the AMIP (right column) experiment.

La Niña simulation, averaged over the region $5.6^{\circ} \mathrm{N}-11.2^{\circ} \mathrm{S}$, $96.6^{\circ} \mathrm{E}-150.9^{\circ} \mathrm{E}$. (This region is plotted in Fig. 1, and hereafter we refer to it as the Indonesian region.) In terms of mass, OC emissions are much larger than those of $\mathrm{SO}_{2}$ and BC.

Note that in these emissions many uncertainties are involved due to difficulties in estimating burned areas (Giglio et al., 2010), emission factors (Andreae and Merlet, 2001) or fuel combustion (van der Werf et al., 2010). As stated by van der Werf et al. (2010), the assessment of uncertainties is difficult due to the lack of sufficient ground truth data; a brief summary of (best-guess) uncertainties can be found in their Table 6. Another source of uncertainty is the omission of secondary organic aerosols, which is likely to contribute to an underestimate of aerosol emissions.

Spatially averaged emission anomalies (El Niño minus La Niña) for the months July through to November are shown in Fig. 1. These are the months in which the GFEDv3 emission estimates suggest the largest anomalies. According to Fig. 1, the main contributing regions are southern Sumatra, southern Borneo (Kalimantan) and to a lesser extent the south-western region of New Guinea.
Table 2. Average annual and July - November emissions of $\mathrm{SO}_{2}$, $\mathrm{OC}$ and $\mathrm{BC}$ (in Tg per month) from the Indonesian region $\left(5.6^{\circ} \mathrm{N}-\right.$ $11.2^{\circ} \mathrm{S}, 96.6^{\circ} \mathrm{E}-150.9^{\circ} \mathrm{E}$ ) for the El Niño (1997) and La Niña (2000) simulation of CLIM and AMIP.

\begin{tabular}{ccc}
\hline & El Niño & La Niña \\
\hline \multicolumn{3}{c}{ annual } \\
\hline $\mathrm{SO}_{2}$ & 1.42 & 0.03 \\
$\mathrm{OC}$ & 8.97 & 0.19 \\
$\mathrm{BC}$ & 1.13 & 0.02 \\
\hline \multicolumn{3}{c}{ July-November } \\
\hline $\mathrm{SO}_{2}$ & 1.35 & 0.02 \\
$\mathrm{OC}$ & 8.52 & 0.11 \\
$\mathrm{BC}$ & 1.07 & 0.01 \\
\hline
\end{tabular}

The difference of the July to November average of the $\mathrm{SO}_{4}, \mathrm{OC}$ and $\mathrm{BC}$ burdens between the El Niño and the La Niña simulation is shown in Fig. 2, from CLIM (left column) and AMIP (right column). In tune with the emissions, in both experiments aerosol loads are largest close to 

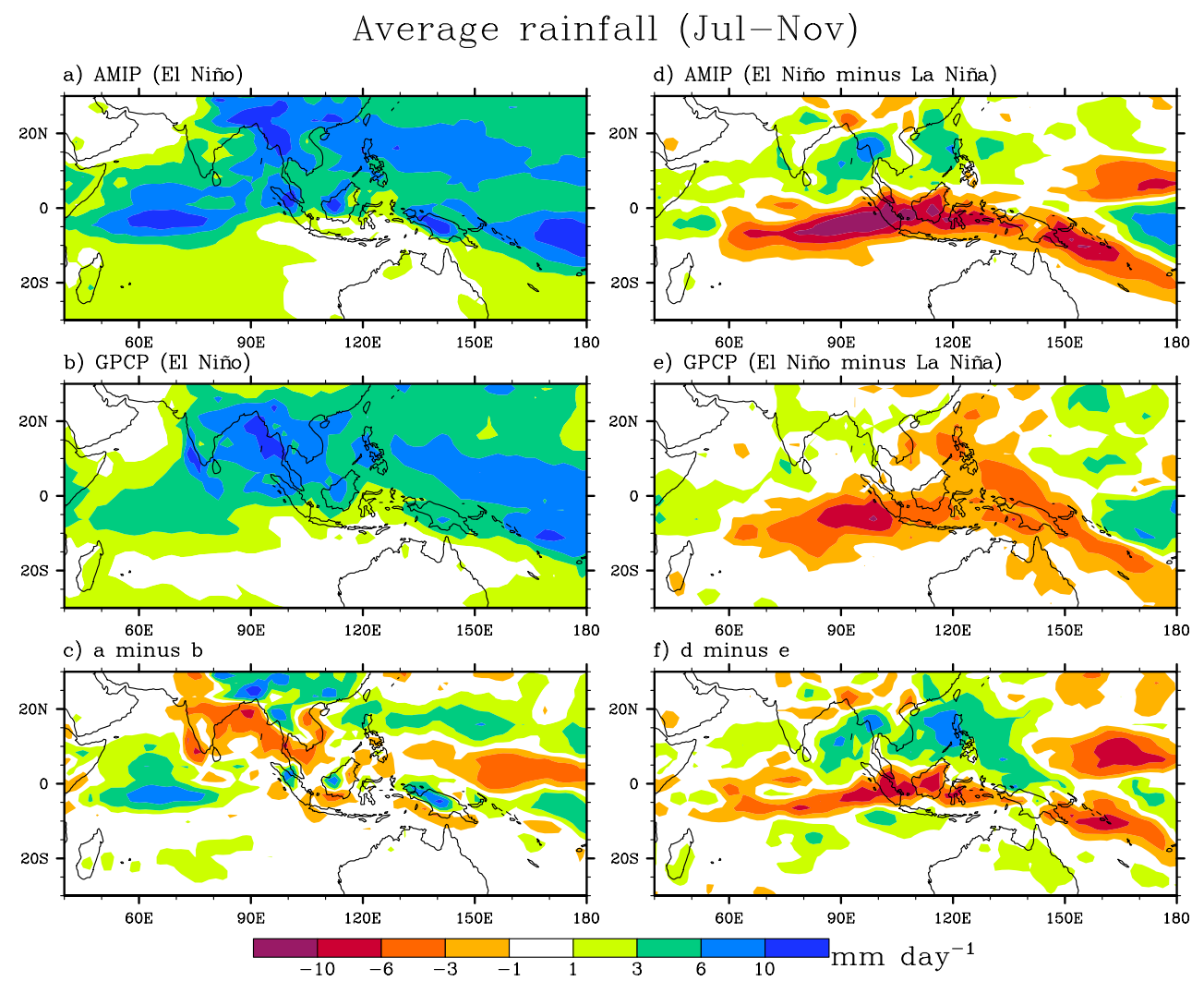

Fig. 3. Average July to November rainfall in the El Niño year 1997 from (a) the AMIP experiment, (b) GPCP dataset and (c) the difference, as well as the SST-induced rainfall anomaly (1997 minus 2000) averaged over the months July to November from the same datasets (d-f).

the major burning regions over south Sumatra and Kalimantan, with a second but much smaller peak over the southwestern region of New Guinea. West of Sumatra over the eastern equatorial Indian Ocean aerosol burdens are substantially raised. However, Fig. 2 indicates that, despite identical emissions in CLIM and AMIP, aerosol loads in AMIP are generally larger and reach further out into the Indian Ocean. This becomes particularly obvious when comparing the panels illustrating the sulphate burdens (panels a and $b$ ). While in CLIM, anomalously high amounts of sulphate remain close to the dominating source regions of Sumatra and Borneo, in AMIP sulphate levels are raised over a region stretching from $60^{\circ} \mathrm{E}$ to $170^{\circ} \mathrm{E}$. Carbonaceous aerosol burdens ( $\mathrm{OC}$ and $\mathrm{BC}$ ) are also enhanced, but not as strongly. The stronger enhancement of sulphate in AMIP occurs because it is scavenged by rainfall more efficiently than $\mathrm{OC}$ and $\mathrm{BC}$; see discussion in Sect. 3.7.

In AMIP, additional regions appear with altered aerosol burdens, which seem not necessarily related to Indonesian biomass burning; this is explained in section 3.2.

\subsection{SST-induced differences in the atmospheric circulation}

In both of our experiments, anomalies in aerosol distribution in the atmosphere are initiated by an El Niño-related increase of BB aerosols from the Indonesian region. The amount of aerosols remaining in the atmosphere, however, is influenced not only by emission strengths, but also by the efficiency of aerosol removal (i.e. dry or wet deposition) and transport. Comparing the AMIP and CLIM experiments, the main differences are caused by differing rainfall and atmospheric circulation patterns induced by SST variations.

\subsubsection{Rainfall patterns}

Due to identical (climatological) SSTs in the CLIM experiment, the atmospheric circulation and rainfall remain unchanged in the El Niño and La Niña simulation. Hence, in the CLIM experiment the pattern of aerosol removal due to rainfall as well as the strength and direction of aerosol transport is the same in both years. This is, however, not the case in the AMIP experiment. Figure 3d shows the average rainfall anomaly (El Niño minus La Niña) of AMIP for the period July to November. Rainfall rates are substantially reduced not only in the Indonesian region. In the region 
from $5^{\circ} \mathrm{N}$ and $10^{\circ} \mathrm{S}$ and $60^{\circ} \mathrm{E}$ and $165^{\circ} \mathrm{E}$, rainfall is generally reduced by more than $6 \mathrm{~mm}^{\text {day }}{ }^{-1}$. Hence, in contrast to CLIM, regions with higher BB emissions coincided with anomalously dry conditions in the AMIP experiment. Therefore, besides a larger amount of aerosols emitted into the atmosphere, aerosol removal is less efficient, so that the lifetime of aerosols is increased during El Niño.

The impact of SSTs on rainfall is also visible outside Indonesia. Over parts of India, the Bay of Bengal and the South China Sea, for instance, a positive rainfall anomaly appears in the AMIP experiment. Increased wet-scavenging of aerosols results in reduced aerosol burdens (see right column panels of Fig. 2) although by design of our experiments the emissions from these regions are equal in the El Niño and La Niña simulations. Similarly, there are positive aerosol anomalies due to small negative rainfall anomalies over China (an area with large aerosol emissions) and over the climatologically dry Arabian peninsula. Note that the scale used for Fig. 3d does not clearly show the small rainfall anomalies over China and the Arabian peninsula.

It is known that atmospheric GCMs generally have problems in simulating rainfall over highly-convective regions. Models often tend to be over-sensitive to SSTs, which can result in an overestimation (Kitoh and Arakawa, 1999; Wu et al., 2006; Martin and Schumacher, 2012) or underestimation (Neale and Slingo, 2003) of rainfall. The problems are likely to be more evident when considering the fine spatial detail over a region such as the Indonesian archipelago, or the diurnal cycle (Neale and Slingo, 2003; Yang and Slingo, 2001; Collier and Bowman, 2004).

We compared the AMIP rainfall to rainfall of corresponding years (1997 and 2000) from the Global Precipitation Climatology Project (GPCP) (Adler et al., 2003; Huffman et al., 2009). In the La Niña simulation of AMIP (not shown), the equatorial region $\left(5^{\circ} \mathrm{S}\right.$ to $5^{\circ} \mathrm{N}$ and $50^{\circ} \mathrm{E}$ to $\left.180^{\circ} \mathrm{E}\right)$ appears on average about $2 \mathrm{~mm}$ day $^{-1}$ too wet, which means that in the La Niña simulation of AMIP the already low aerosol burdens get removed very quickly. Conversely, India, Thailand and the Philippines (from $5^{\circ} \mathrm{N}$ to $20^{\circ} \mathrm{N}$, and $70^{\circ} \mathrm{E}$ to $140^{\circ} \mathrm{E}$ ) are on average about $2.9 \mathrm{~mm} \mathrm{day}^{-1}$ too dry. The El Niño simulation of AMIP (Fig. 3, left column) is closer to the GPCP estimates than the La Niña simulation. Over the Indonesian region too wet patches alternate with too dry patches, so it is expected that the area-averaged rainfall during El Niño is modelled reasonably well.

Comparing the anomaly (El Niño minus La Niña) of rainfall from AMIP and GPCP (Fig. 3, right column), it is seen that in both datasets the dominating negative rainfall anomaly is located west of Sumatra in the equatorial Indian Ocean. The anomaly, however, appears stronger in AMIP. While the GPCP data suggests that in this region the difference between the El Niño and La Niña year lies between -6 and $-12 \mathrm{~mm}$ day $^{-1}$ during the specified months, the rainfall anomaly exceeds $-12 \mathrm{~mm} \mathrm{day}^{-1}$ in the AMIP experiment. The GPCP rainfall anomaly indicates that anomalously dry conditions
Table 3. Average July-November rainfall (in mm per day) in the Indonesian region $\left(5.6^{\circ} \mathrm{N}-11.2^{\circ} \mathrm{S}, 96.6^{\circ} \mathrm{E}-150.9^{\circ} \mathrm{E}\right)$ in 1997,2000 and the difference between both years (1997 minus 2000) from the AMIP and the CLIM simulations as well as from the observational datasets GPCP and CMAP.

\begin{tabular}{lccc}
\hline & 1997 & 2000 & 1997 minus 2000 \\
\hline AMIP & 3.62 & 7.47 & -3.85 \\
CLIM & 6.15 & 6.15 & 0.00 \\
GPCP & 3.54 & 6.76 & -3.23 \\
CMAP & 2.90 & 6.64 & -3.74 \\
\hline
\end{tabular}

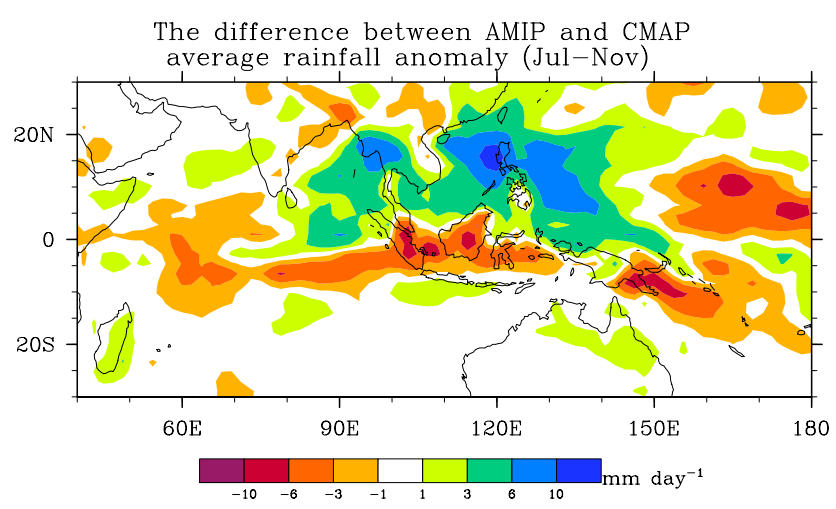

Fig. 4. Same as Fig. 3f, but using rainfall observations from CMAP instead of GPCP.

were also present in the Philippines, Cambodia, Laos and Vietnam. In AMIP there is an anomaly of opposite sign, however, as those regions lie outside our study area this does not affect the results of this study.

To check these results, we repeated the comparison using observations from the Climate Prediction Center Merged Analysis of Precipitation (CMAP; Xie and Arkin, 1997). Comparing Fig. 4 with Fig. 3f, it is seen that broad pattern of the model bias is similar, with a rainfall anomaly that is too strongly concentrated in a narrow band along the equator. However, this feature appears less severe when data from CMAP are used, and the model's excessive negative rainfall anomaly over Sumatra and Borneo is reduced in magnitude.

Average July to November rainfall over the Indonesian region is summarised in Table 3 for the model and observations. It is seen that the rainfall anomaly (third column) in AMIP is somewhat overestimated with respect to GPCP, but agrees well with CMAP. Careful inspection of Figs. $3 \mathrm{f}$ and 4 shows that relatively good agreement between the modelled and observed area-averaged rainfall anomaly occurs partly due to cancellation of errors of opposite sign in different parts of the Indonesian region. In particular, a positive bias over the ocean north of New Guinea partly offsets the negative bias over Sumatra and Borneo.

Although it is difficult to be precise, these points suggest that the rainfall biases in the model contribute to a modest 


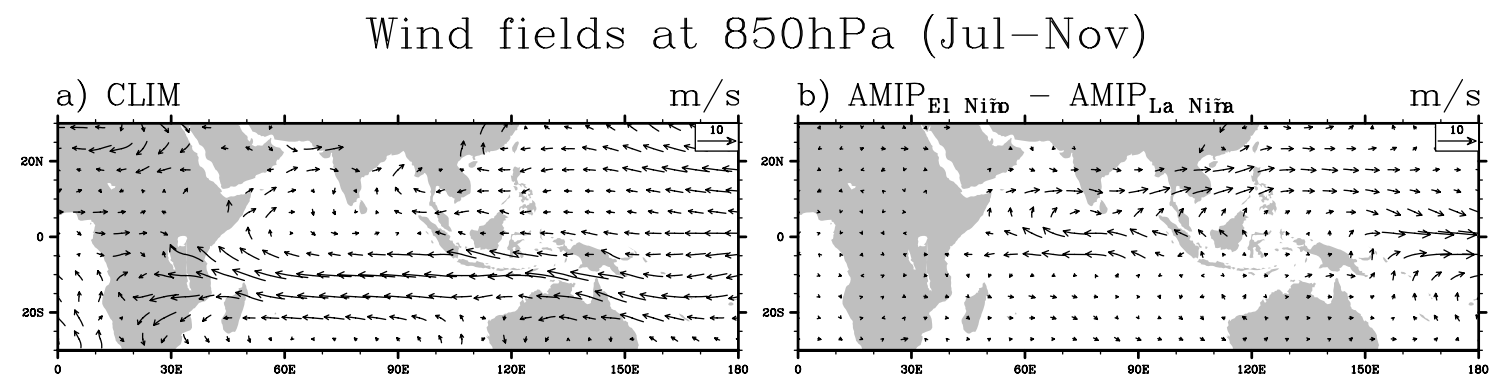

Fig. 5. (a) The mean July to November $850 \mathrm{hPa}$ wind fields that apply for both the El Niño and La Niña cases of the CLIM experiment, and (b) the wind anomaly (El Niño minus La Niña) from the AMIP experiment averaged over the same months.

overestimate of the AOD and radiative forcing anomalies. The overly strong rainfall anomaly in AMIP occurs mainly over the strong emission source regions of Sumatra and Borneo, implying an overestimate of the ENSO-induced change in wet scavenging of aerosols. However, the bias occurs mainly in the La Niña simulation, when aerosol emissions are low (Table 2), and this will reduce the effect of the rainfall bias. Rainfall during the high-emission phase (El Niño) is simulated much better. More generally, the ENSO-related rainfall anomaly is too strongly concentrated in a narrow band along the equator, and this will affect the simulated spatial pattern of the radiative forcing anomalies. Note, however, that the lack of secondary organic aerosols in the GFED3 emission estimates contributes to an underestimation of AODs (see Sect. 3.3); this exerts an impact on AOD and radiative forcing anomalies of opposite sign (see Sects. 3.3 and 3.8 for more details).

\subsubsection{Wind patterns}

Figure 5a shows the mean July to November $850 \mathrm{hPa}$ wind fields that apply for both the El Niño and La Niña simulation of CLIM. In the entire Indonesian region easterly winds prevail with stronger winds south of the equator. CLIM wind fields are similar to the La Niña situation in AMIP; the latter indicates slightly weaker winds over the equatorial Indian Ocean and somewhat stronger winds east of New Guinea (not shown).

Figure $5 \mathrm{~b}$ shows the $850 \mathrm{hPa}$ wind anomaly (El Niño minus La Niña) from the AMIP simulation, averaged over the months July to November. There are mainly two regions in which wind changes affecting the Indonesian region become apparent. In the El Niño simulation, stronger easterly winds form west of about $120^{\circ} \mathrm{E}$ so that air masses from the main islands Sumatra and Borneo are directed away from Indonesia into the Indian Ocean. East of $150^{\circ} \mathrm{E}$ the wind anomaly indicates westerly winds, resulting from weaker easterly winds during El Niño through a weakening of the Walker Circulation. Here, the aerosol transport would be reduced.
Since the La Niña simulation in AMIP has similar winds to CLIM, wind fields in the El Niño simulations show distinct differences in AMIP and CLIM. In regions west of $120^{\circ} \mathrm{E}$, easterly winds were much stronger in AMIP, so that in CLIM aerosols are likely to be much less efficiently transported away from the burning regions.

A very similar conclusion was drawn by Heil et al. (2007) who compared analysed wind fields during an ENSO-neutral year (1996) and the El Niño year 1997 in an air-quality study. Although our CLIM simulation exhibits a weaker southerly wind component, the general features of the 1996 wind fields (see their Fig. 5) correspond to our climatological simulation. The wind patterns during the dry season in 1997 resemble the El Niño simulation of AMIP (not shown), and are also in agreement with the October reanalysed wind field in 1997 shown by Parameswaran et al. (2004). Heil et al. (2007) stated that the more pronounced (south-)easterly winds associated with El Niño contributed to the increased spatial expansion of the smoke haze layer in 1997, while under ENSOneutral conditions the aerosol layer is confined much more to the source regions. This is in agreement with our findings.

\subsection{Aerosol optical depths}

The anomaly of the clear-sky aerosol optical depths (AODs) averaged for the period July to November are presented in Fig. 6. As a result of differing aerosol distributions, the AODs in CLIM and AMIP vary markedly. As in CLIM, the source of the BB aerosols is clearly visible, showing positive anomalies over the main burning regions and in the eastern Indian Ocean. In AMIP, however, the AOD anomaly is substantially larger and stretches further to the west into the Indian Ocean. As a result, during El Niño AODs are raised from $60^{\circ} \mathrm{E}$ through to about $150^{\circ} \mathrm{E}$. Enhanced AODs are also visible south of the Arabian Peninsula and the Northern Arabian Sea, which are not a result of Indonesian BB. Rather, dust particles that are advected from the African continent as well as rainfall-related higher $\mathrm{SO}_{4}$ loads in 1997 lead to increases in the AODs (see Sects. 3.1 and 3.2).

We compared CLIM and AMIP clear-sky AODs at $550 \mathrm{~nm}$ with satellite-derived AODs from the sensors MODIS 
Anomaly of aerosol clear-sky optical depth

a) CLIM

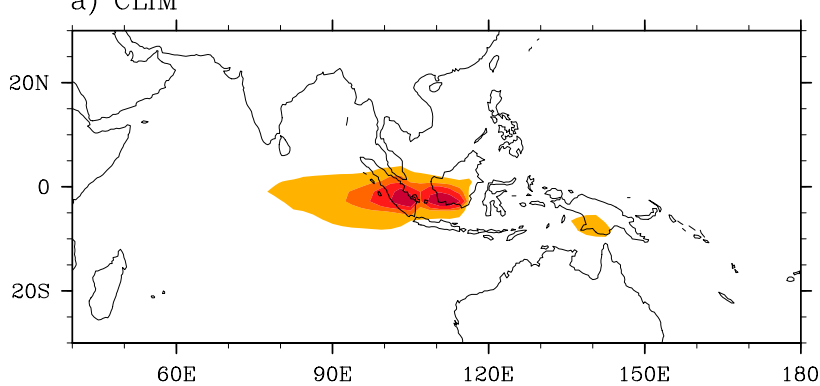

b) AMIP

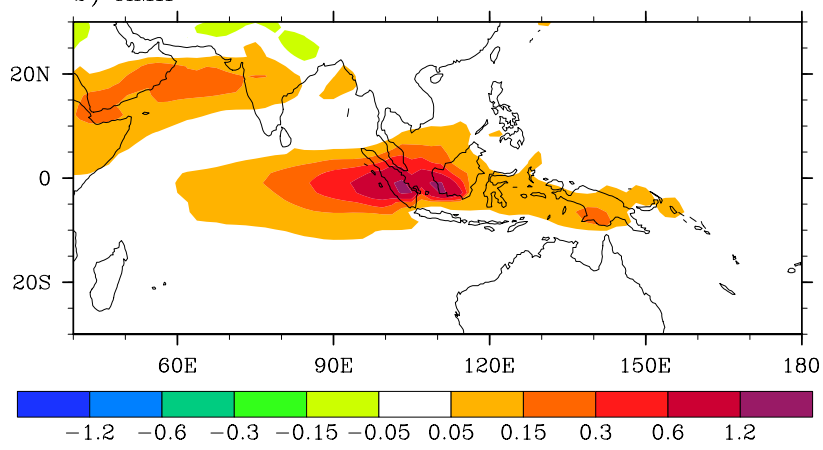

Fig. 6. Anomaly (El Niño minus La Niña) of aerosol clear-sky optical depth at $550 \mathrm{~nm}$ from the (a) CLIM and the (b) AMIP experiment averaged for the period July to November.

(Moderate Resolution Imaging Spectroradiometer) (King et al., 2003; Remer et al., 2005) and MISR (Multi-angle Imaging SpectroRadiometer) (Chen et al., 2008; Kahn et al., 2005). Due to a lack of data for the year 1997, we use retrievals from the El Niño years 2002, 2004 and 2006 and the La Niña years 2000, 2001 and 2005. This implies that absolute agreement cannot be expected for 1997. For this reason, we also include monthly mean AODs based on the same El Niño $(2002,2004,2006)$ and La Niña $(2000,2001,2005)$ years as for the satellite data from the extended AMIP run and refer to this as "AMIP*".

Monthly averaged AODs from CLIM, AMIP and AMIP* as well as from MODIS and MISR are presented in Fig. 7. The Figure indicates that AODs in the La Niña and the first half of the El Niño simulation seem to be systematically underestimated by about 0.05 to 0.1 in all model runs (CLIM, AMIP and AMIP*). During the drier months of the El Niño simulation, both CLIM and AMIP AODs lie within the range of the satellite retrievals, but AMIP* AODs remain smaller than those from MODIS and MISR throughout the drier months of El Niño. Note that the 1997 El Niño event was a much stronger event than those for which satellite retrievals are available. Hence, it is likely that AODs suggested by MODIS and MISR in Fig. 7a are a rather low estimate for 1997. These results indicate a general tendency within our simulations to underestimate AODs in the Indonesian region.
Several factors are likely to contribute to an underestimation of modelled AODs. One major point is that the formation of aerosols due to gas-to-particle formation is not taken into account for the emission estimates of GFED. Secondary organic aerosols (SOAs) can contribute substantially to the amount of regional aerosol loads. Grieshop et al. (2009) and Iinuma et al. (2010), for instance, stated that SOAs may increase aerosol burdens by a factor of 1.5 to 2.8 . In addition, van der Werf et al. (2010) stated that the emission estimates are likely to be too low due to uncertainties in burned area estimates. It is possible to use inverse modelling combined with satellite-retrieved AODs to estimate emissions (Zhang et al., 2005), although this would be beyond the scope of our study.

Another factor that may influence AODs is the tendency of our model to overestimate rainfall in the equatorial region. As previously discussed in Sect.3.2.1, this is more pronounced for the La Niña simulations.

The tendency of our model to underestimate AODs is associated with an underestimate of scattering and absorption of solar radiation so that the diagnosed magnitude of aerosol direct radiative forcing is likely to be too low. The same does not necessarily follow for the indirect aerosol effect as this strongly depends on the model parametrization for cloud droplet number concentration.

\subsection{Anomalies in the direct aerosol forcing}

The direct radiative forcing anomaly for the Indonesian region, defined as the difference between 1997 and 2000 conditions, is shown on a monthly basis in Fig. 8. In both experiments, substantial radiation anomalies are present in the months July through to November. Despite the fact that the injected aerosol emissions are identical in CLIM and AMIP, the radiative impact of increased $\mathrm{BB}$ aerosols is larger in the AMIP experiment.

In AMIP, the strongest difference between the El Niño and La Niña simulation occurs in September: at the surface anomalies amount to $-15 \mathrm{Wm}^{-2}$ while at the same time the top of atmosphere (TOA) radiation is reduced by $3 \mathrm{Wm}^{-2}$. In CLIM, the magnitude of the direct forcing anomaly peaks in October with about $-9 \mathrm{Wm}^{-2}$ at the surface and around $-2 \mathrm{Wm}^{-2}$ at the TOA. During the entire burning period, CLIM direct forcing anomalies remain weaker than the anomalies in AMIP. The larger difference between the radiative forcing at the surface and the TOA in the AMIP experiment indicates that stronger atmospheric heating due to aerosol absorption also takes place in the AMIP experiment.

Figure 9 shows the CLIM (panel a) and AMIP (panel b) direct forcing anomaly at the surface, averaged over the months July to November. Panel c of Fig. 9 illustrates the difference between panel $b$ and panel a (AMIP minus CLIM).

While the largest radiative perturbations occur close to the source regions, El Niño-related aerosol emissions spread out and reduce surface radiation in much of the Indian Ocean 

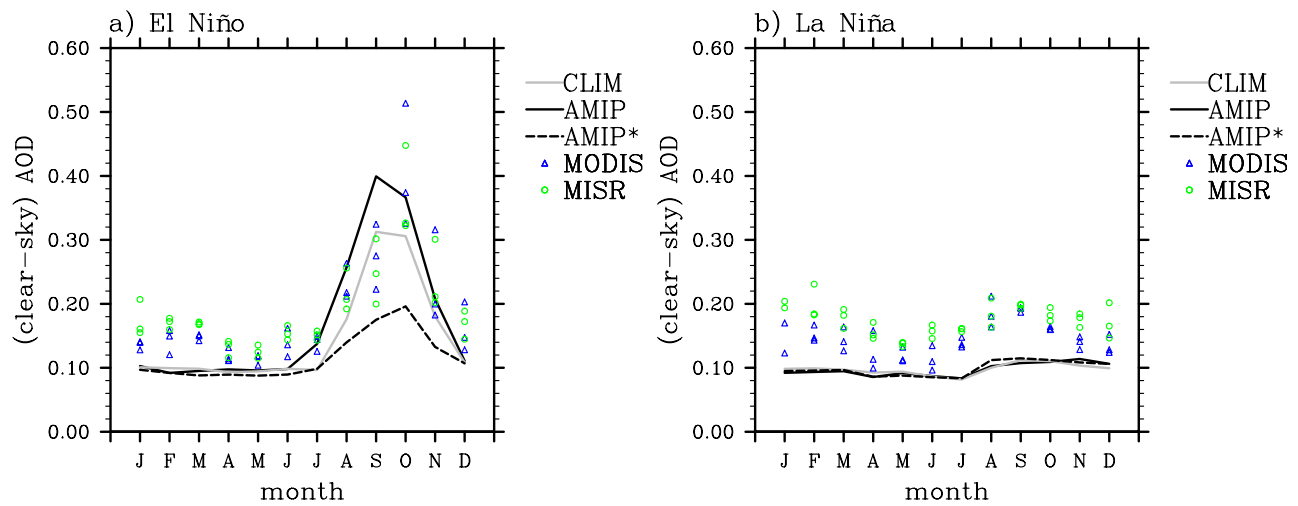

Fig. 7. Aerosol optical depths (AODs) at $550 \mathrm{~nm}$ of CLIM (grey), AMIP (black, solid line) and AMIP* (black, dashed line) representing average (a) El Niño and (b) La Niño conditions over the Indonesian region $\left(5.6^{\circ} \mathrm{N}-11.2^{\circ} \mathrm{S}, 96.6^{\circ} \mathrm{E}-150.9^{\circ} \mathrm{E}\right)$ in comparison with MODIS (blue triangle) and MISR (green circle) measurements. AODs from the CLIM and AMIP experiment simulate the year-1997 El Niño and the year-2000 La Niña. The satellite retrievals MODIS and MISR are from the El Niño years 2002, 2004 and 2006 and the La Niña years 2000 , 2001 and 2005, respectively. AMIP* represents monthly mean AODs based on the same years as the satellite data.

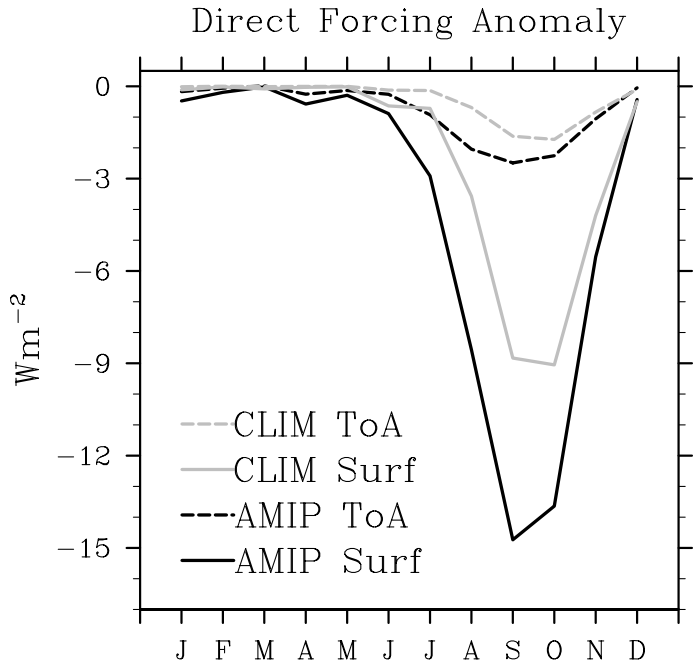

Fig. 8. Direct forcing anomaly (El Niño minus La Niña) for the Indonesian region $\left(5.6^{\circ} \mathrm{N}-11.2^{\circ} \mathrm{S}, 96.6^{\circ} \mathrm{E}-150.9^{\circ} \mathrm{E}\right)$ at the top of atmosphere (dashed) and the surface (solid) from the CLIM (grey) and AMIP (black) experiment.

and parts in the western equatorial Pacific. In both experiments, perturbations are strongest west of Sumatra in the eastern equatorial Indian Ocean. In the AMIP simulation, however, the radiative impact is substantially enhanced both in strength and spatial extent (Fig. 9c). In the eastern Indian Ocean, for instance, the area in which surface radiation is reduced by more than $10 \mathrm{Wm}^{-2}$ extends further to the west and south. In a large area the magnitude of the forcing anomaly is at least $10 \mathrm{Wm}^{-2}$ stronger. AMIP also shows amplified direct forcing anomalies east of the main burning regions into the equatorial Pacific.

Although AMIP direct forcing anomalies are generally stronger, Fig. $9 \mathrm{c}$ indicates that close to the main source

\section{Direct Forcing Anomaly at the surface (July - November)}

a) CLIM
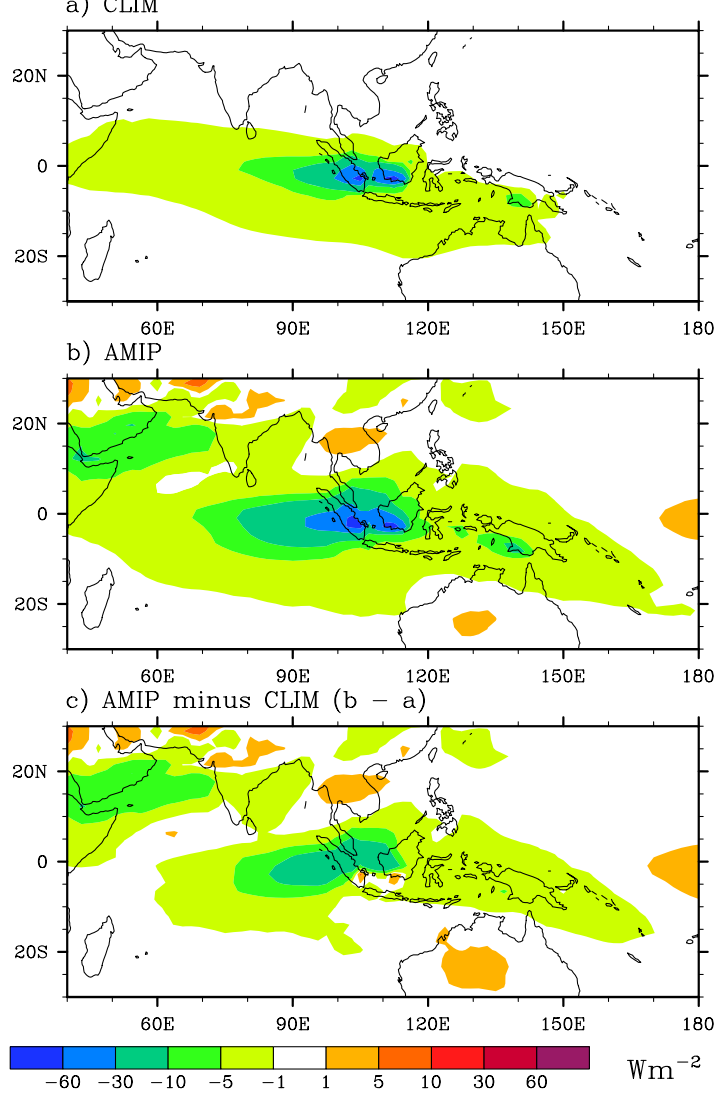

Fig. 9. Average July-November direct forcing anomaly (El Niño minus La Niña) from (a) the CLIM and (b) AMIP experiment and (c) the difference between AMIP and CLIM. 



e) AMIP Indirect Forcing
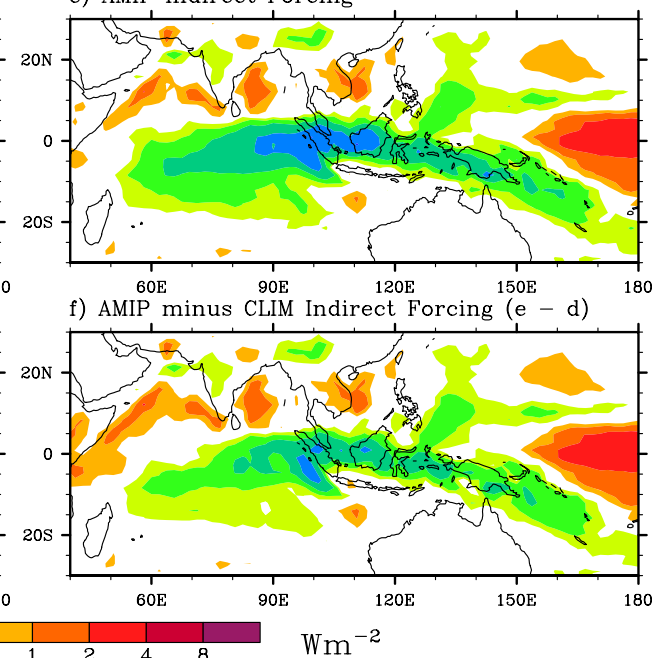

Fig. 10. Average July-November direct (left column) and indirect (right column) forcing anomaly (El Niño minus La Niña) from the CLIM (top) and AMIP (middle) experiment and the difference between AMIP and CLIM (bottom).

regions (i.e. southern Sumatra and Kalimantan), there are small areas where the direct forcing anomaly is stronger in CLIM. This is most likely caused by a weaker horizontal transport from the main emission regions in CLIM (see Sect. 3.2.2).

The direct forcing anomaly at the TOA (left column of Fig. 10) is generally weaker, but shows a very similar pattern to the surface forcing anomaly displayed in Fig. 9. This is true for both CLIM and AMIP. The areas with strongest forcing anomalies (exceeding $-8 \mathrm{Wm}^{-2}$ ) occur over the main emission regions. Over much of the Indian Ocean a weaker anomaly $\left(-1 \mathrm{Wm}^{-2}\right.$ to $\left.-2 \mathrm{Wm}^{-2}\right)$ occurs. An area of similar strength is also present in the eastern equatorial Pacific in the AMIP experiment, which does not appear in CLIM. As a result of increased low cloudiness south of Sumatra in the El Niño simulation of AMIP, BC absorption becomes apparent in a short tongue with a positive forcing anomaly of up to $2 \mathrm{Wm}^{-2}$. The increase of low cloudiness is caused by a more stable boundary layer over anomalously cool SST, associated with the strong positive Indian Ocean Dipole event that occurred in 1997.

An experiment comparable to CLIM for the direct forcing anomaly can be found in Tosca et al. (2010). They give estimates from the same years (1997 minus 2000) based on a background of climatological conditions, but for a slightly smaller region $\left(5^{\circ} \mathrm{N}-5^{\circ} \mathrm{S}, 90^{\circ} \mathrm{E}-120^{\circ} \mathrm{E}\right)$. Tosca et al. found that during August to October SW radiation at the surface was reduced by about $19 \mathrm{Wm}^{-2}$, and nearly zero at the TOA (see their Fig. 3). For the same region and time period, the direct forcing anomaly from the CLIM experiment was similar, both at the surface and TOA $\left(-17 \mathrm{Wm}^{-2}\right.$ and $-3 \mathrm{Wm}^{-2}$, respectively). Note that when the influence of ENSO is considered in AMIP, radiative forcing in the same region becomes significantly enhanced $\left(-30 \mathrm{Wm}^{-2}\right.$ at the surface and $-5 \mathrm{Wm}^{-2}$ at TOA). Tosca et al. noted that their model substantially underestimated fire-induced changes in AOD, and thus the likely magnitude of climatic feedbacks. Our results suggest that this was partly because they used a background of climatological conditions, which did not attempt to capture ENSO-related changes in large-scale circulation.

We also performed a comparison using other studies that looked into the direct radiative effect from the 1997 fires. Note that for this purpose we used actual numbers of the El Niño simulation instead of the forcing anomaly. Duncan et al. (2003) showed October-average direct radiative forcing estimates for the surface derived from an atmospheric chemistry model, considering carbonaceous aerosols only. However, they utilized a rather coarse scale for presenting 


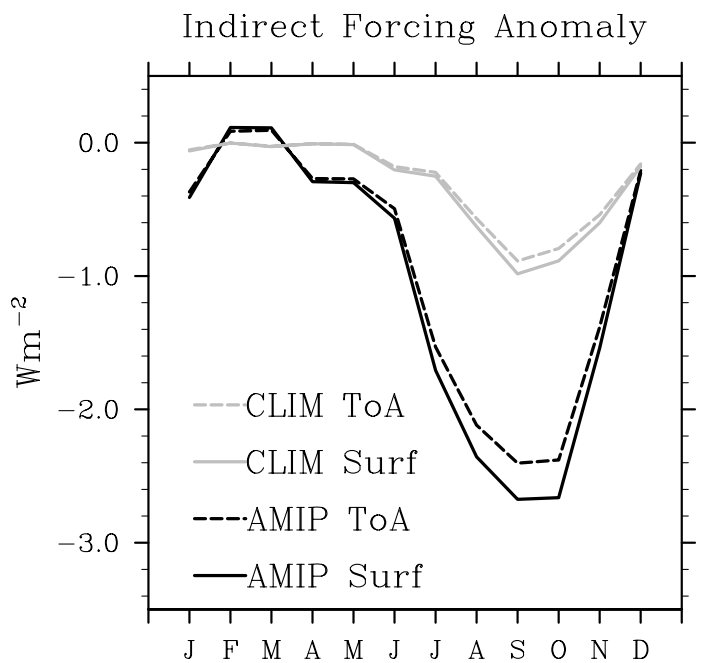

Fig. 11. Indirect forcing anomaly (El Niño minus La Niña) for the Indonesian region $\left(5.6^{\circ} \mathrm{N}-11.2^{\circ} \mathrm{S}, 96.6^{\circ} \mathrm{E}-150.9^{\circ} \mathrm{E}\right)$ at the top of atmosphere (dashed) and the surface (solid) from the CLIM (grey) and AMIP (black) experiment.

their results, so it is difficult to be precise. Comparison with their Figure 20 suggests that CLIM and AMIP give roughly comparable estimates to theirs, both in extent and in magnitude. A better comparison can be achieved with Rajeev et al. (2008), who presented direct forcing estimates derived from satellite retrievals (their Fig. 1). Their results suggest that the spatial extent of the radiative perturbations is captured much better in the AMIP simulation than in CLIM. Although the magnitude is lower in both of our experiments (possibly for the reasons stated in Sect. 3.3), estimates from AMIP seem more realistic than from CLIM.

\subsection{Anomalies in the indirect aerosol forcing}

The impact of increased aerosol loads during El Niño can also be seen for the indirect forcing. Figure 11 shows the anomalies of indirect forcing within the Indonesian region that are caused by aerosol-induced cloud-albedo changes. In both experiments, the magnitude of the forcing anomalies at the surface and the TOA are of similar strength. Similar to the direct forcing, the impact of increased aerosol burdens on indirect forcing is amplified in AMIP, but with a less dramatic effect on the surface radiation budget over Indonesia. In CLIM, altered cloud properties cause a radiation reduction, mostly evident between June to November. The strongest forcing $\left(-1 \mathrm{Wm}^{-2}\right)$ occurs in September. In AMIP, the indirect forcing anomalies are present throughout the year. In tune with a positive rainfall anomaly of about $0.5 \mathrm{~mm}$ day $^{-1}$ during the months February and March (not shown), AMIP indirect forcing anomalies are slightly positive during this period. In the remaining months, indirect forcing anomaly is negative, with a steep decrease from July

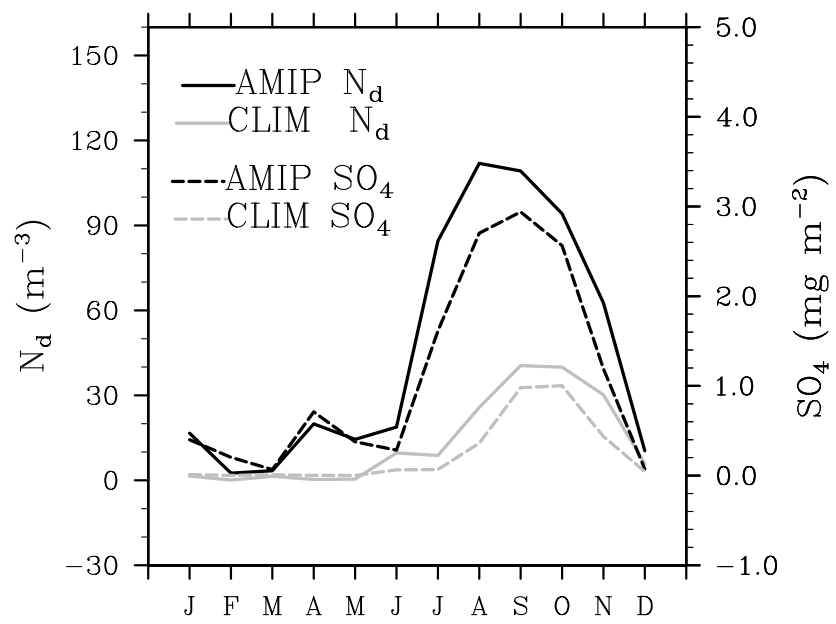

Fig. 12. Monthly anomaly (El Niño minus La Niña) of the cloud droplet number concentration $\left(N_{\mathrm{d}}\right.$ in $\mathrm{cm}^{-3}$, solid lines) and sulphate burdens $\left(\mathrm{SO}_{4}\right.$ in $\mathrm{mg} \mathrm{m}^{-2}$, dashed lines) within the Indonesian region $\left(5.6^{\circ} \mathrm{N}-11.2^{\circ} \mathrm{S}, 96.6^{\circ} \mathrm{E}-150.9^{\circ} \mathrm{E}\right)$ of the CLIM (grey) and the AMIP (black) experiment.

down to $-2.7 \mathrm{Wm}^{-2}$ in September and October. This again gives a stronger radiative forcing than in CLIM.

The right column of Fig. 10 shows the TOA indirect forcing anomaly of CLIM, AMIP and the difference of AMIP and CLIM (panels d-f, respectively). Note that the indirect forcing anomaly at the surface looks very similar (not shown). In both CLIM and AMIP, the areas with the largest indirect forcing anomalies are located over and close to the main emission regions. The perturbations in AMIP are throughout stronger than in CLIM, reaching -4 to $-8 \mathrm{Wm}^{-2}$ and -2 to $-4 \mathrm{Wm}^{-2}$, respectively. Although of comparable strength and spatial scale, the pattern of the indirect radiative perturbations differs slightly from the direct forcing anomaly presented in Fig. 10. Areas in which the amplification of the forcing is evident stretch in a rather narrow band from the Indian Ocean across the Indonesian region towards the western Pacific (see Fig. 10f). Unlike the direct forcing anomaly (panel c), in which stronger forcing is mostly apparent west of $110^{\circ} \mathrm{E}$, the differences in the indirect forcing are of almost equal strength throughout the entire region.

The pattern of the indirect forcing anomaly resembles the rainfall anomaly in the corresponding period (Fig. 3d), indicating a strong influence of the rainfall on the indirect forcing anomaly. This will be discussed in more detail in the following sections. As previously mentioned, the rainfall anomaly in the model is too strongly concentrated in a narrow band along the equator, and this is likely reflected in the spatial pattern of the indirect forcing anomaly seen in Fig. 10f.

\subsection{Aerosol-induced cloud property changes}

The indirect forcing results from aerosol-induced cloud property changes. This is discussed in this subsection. 


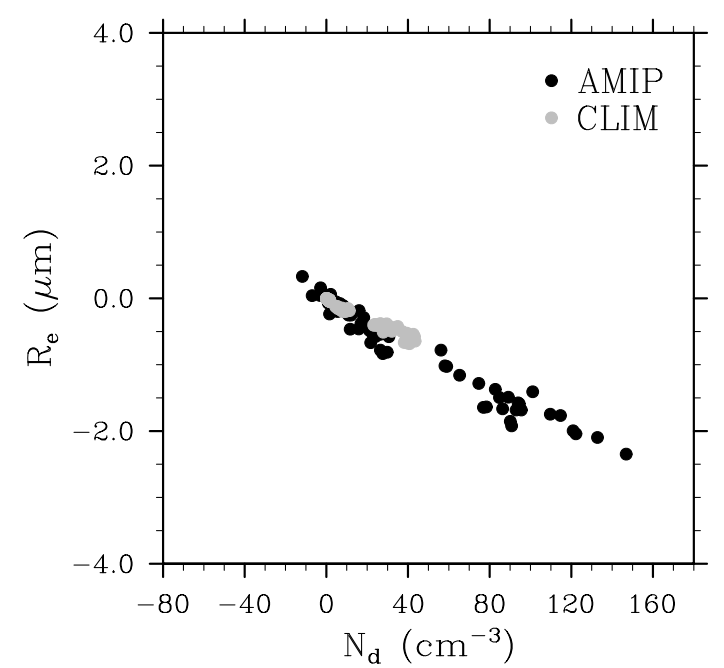

Fig. 13. Monthly anomaly (El Niño minus La Niña) of the cloud effective radius $\left(R_{\mathrm{e}}\right.$ in $\left.\mu \mathrm{m}\right)$ for the Indonesian region $\left(5.6^{\circ} \mathrm{N}-11.2^{\circ} \mathrm{S}\right.$, $\left.96.6 \mathrm{E}^{\circ}-150.9^{\circ} \mathrm{E}\right)$ as a function of the monthly anomaly of the cloud droplet number concentration $\left(N_{\mathrm{d}}\right.$ in $\left.\mathrm{cm}^{-3}\right)$ for each ensemble member of the CLIM (grey) and AMIP (black) experiment.

\subsubsection{Cloud droplet numbers}

The cloud droplet number concentration $\left(N_{\mathrm{d}}\right)$ is dependent on the concentration of hydrophilic aerosols, as they are assumed to act as cloud condensation nuclei (Eq. 1). Monthly $N_{\mathrm{d}}$ anomalies for the CLIM (dashed) and AMIP (solid) experiments are shown in Fig. 12 together with corresponding $\mathrm{SO}_{4}$ burdens as a surrogate for hydrophilic aerosols in the Indonesian region. In CLIM, the $N_{\mathrm{d}}$ anomaly mainly reflects the raised biomass-burning emissions from fires during El Niño. The number of cloud droplets increases slightly in June and reaches its highest anomaly in September and October with about 40 droplets per $\mathrm{cm}^{3}$. In AMIP, the $N_{\mathrm{d}}$ anomaly shows different behaviour, with a rapid increase after June. During August and September, the $N_{\mathrm{d}}$ anomaly in AMIP exceeds 100 droplets per $\mathrm{cm}^{3}$.

The much stronger increase of $N_{\mathrm{d}}$ after June in AMIP can be attributed to the dependence of the number of cloud droplets on the concentration of hydrophilic aerosols (Eq. 1). Sulphate and the hydrophilic forms of BC and OC are efficiently scavenged by rainfall (Rotstayn and Lohmann, 2002), the latter ones to a slightly lesser degree. In the El Niño simulation of AMIP, the Indonesian region experiences a sharp decrease of rainfall between June $\left(6.4 \mathrm{~mm} \mathrm{~d}^{-1}\right)$ and July $\left(3.4 \mathrm{~mm} \mathrm{~d}^{-1}\right)$. A negative rainfall anomaly from July onwards in 1997 exerts a strong positive feedback on the number of cloud droplets.

\subsubsection{Cloud droplet sizes}

Figure 13 shows the monthly anomaly in cloud droplet effective radii $\left(R_{\mathrm{e}}\right)$ as a function of the $N_{\mathrm{d}}$ anomaly from the
CLIM (grey) and AMIP (black) experiments. The data points are highly correlated, both in CLIM $(r=-0.99)$ and AMIP $(r=-0.98)$. In CLIM, the rather minor increase in cloud droplets results in a similarly small decrease in the size of the cloud droplets with a maximum decrease of $0.6 \mu \mathrm{m}$. As the response in the number of cloud droplets is larger in AMIP, the size decrease of cloud droplets is likewise more pronounced. As a consequence of a larger number of smaller cloud droplets in AMIP, the cloud albedo increases so that more solar radiation is reflected back to space than in CLIM (see Sect. 3.5).

Based on estimates from CERES (Clouds and Earth's Radiant Energy System) (Minnis et al., 2011; Wielicki et al., 1996) and MODIS (King et al., 2003), we performed a comparison with $R_{\mathrm{e}}$ estimates suggested by our model results. Both datasets are based on (daytime) Terra-MODIS satellite retrievals but are processed differently. As in the AOD comparison above, we used available data covering the years 2002, 2004 and 2006 and 2000 (February to December), 2001 and 2005 for El Niño and La Niña, respectively, and completed the analysis by including $R_{\mathrm{e}}$ from the extended AMIP run (AMIP*), representing an average over the same El Niño and La Niña years as for the satellite data.

Average July-November $R_{\mathrm{e}}$ for the Indonesian region are presented in Table 4 for all datasets. Generally, modelled $R_{\mathrm{e}}$ are smaller than measured cloud droplet sizes from MODIS and CERES, while $R_{\mathrm{e}}$ estimated from MODIS are larger than from CERES. A likely explanation for the smaller values of $R_{\mathrm{e}}$ in the model is that drizzle and raindrops are not included in the calculation of $R_{\mathrm{e}}$ (or radiative transfer) in the model. In common with many other GCMs, the cloud scheme in Mk3.6 uses the "autoconversion" approach, which represents the conversion of cloud droplets to precipitating drops, and the latter are assumed to rapidly fall out of the atmosphere. In contrast, the MODIS retrievals do include the effects of drizzle droplets (e.g., Suzuki et al., 2010), and these will tend to increase the retrieved droplet sizes in CERES and MODIS. The general disagreement between $R_{\mathrm{e}}$ estimates from CERES and MODIS has been discussed previously by Minnis et al. (2011). They concluded that the use of different channels, i.e. $2.1 \mu \mathrm{m}$ in MODIS and $3.8 \mu \mathrm{m}$ in CERES, caused a detection of larger cloud droplets in MODIS, as the vertical sampling of cloud droplets went deeper into the cloud using smaller wavelengths (Platnick, 2000). Minnis et al. (2011) also pointed out that the largest discrepancies between MODIS and CERES were present over tropical marine areas, which includes the broader Indonesian region. Note that, as stated by Minnis et al. (2011), these results suggest that smaller droplets are generally located at the cloud top, which differs from the typical adiabatic profile of nonprecipitating clouds, but more research is needed to determine if the effect is real.

The average anomaly of $R_{\mathrm{e}}$ during the months July to November is much larger in AMIP than seen in the other datasets (rightmost column in Table 4). In contrast, the 
Table 4. Average July-November cloud droplet effective radius $\left(R_{\mathrm{e}}\right.$ in $\mu \mathrm{m})$ in the Indonesian region region $\left(5.6^{\circ} \mathrm{N}-11.2^{\circ} \mathrm{S}, 96.6^{\circ} \mathrm{E}-\right.$ $150.9^{\circ} \mathrm{E}$ ) from CERES and MODIS (satellite retrievals are grey shaded) and the model experiments CLIM, AMIP and AMIP* for El Niño and La Niña conditions as well as the corresponding $R_{\mathrm{e}}$ anomaly (El Niño minus La Niña). For CERES, MODIS and AMIP* El Niño represents the average of the years 2002, 2004 and 2006, and La Niña of 2000, 2001 and 2005. CLIM and AMIP represent the El Niño of 1997 and the La Niña of 2000.

\begin{tabular}{cccc}
\hline & El Niño & La Niña & anomaly \\
\hline CERES & 12.8 & 13.1 & -0.3 \\
MODIS & 16.3 & 17.0 & -0.7 \\
CLIM & 10.1 & 10.6 & -0.4 \\
AMIP & 9.3 & 10.9 & -1.6 \\
AMIP* & 10.0 & 10.8 & -0.7 \\
\hline
\end{tabular}

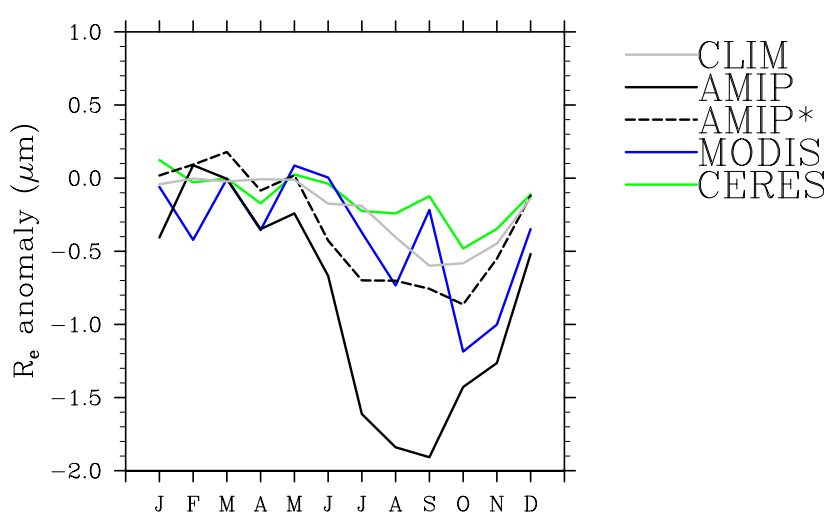

Fig. 14. Comparison of the monthly cloud effective radius $\left(R_{\mathrm{e}}\right)$ anomaly (El Niño minus La Niña) within the Indonesian region $\left(5.6^{\circ} \mathrm{N}==11.2^{\circ} \mathrm{S}, 96.6^{\circ} \mathrm{E}-150.9^{\circ} \mathrm{E}\right)$ from the AMIP (black, solid), AMIP* (black, dashed) and CLIM (grey) experiment with satellite retrievals from MODIS (blue) and CERES (green). The anomaly of AMIP and CLIM are based on the El Niño and La Niña years 1997 and 2000, respectively. The anomalies of the satellite retrievals as well as of AMIP* are based on the El Niño years 2002, 2004 and 2006 and the La Niña years 2000, 2001 and 2005.

anomaly of AMIP* is of the same magnitude as MODIS. The average change in $R_{\mathrm{e}}$ in the CLIM experiment appears to be fairly small and comparable to CERES. Since the satellite retrievals and AMIP* are based on weaker El Niño events, the strong anomaly in AMIP is likely to be a result from high emissions during the very strong El Niño event in 1997 rather than a bias in the model. Consequently, the $R_{\mathrm{e}}$ anomaly in the CLIM experiment is likely to represent an underestimate.

The temporal development of the $R_{\mathrm{e}}$ anomalies (El Niño minus La Niña) is presented in Fig. 14. All of the above datasets have a distinct negative $R_{\mathrm{e}}$ anomaly throughout the dry period. In agreement with Table 4 , the maximum $R_{\mathrm{e}}$ decrease in CLIM $(0.6 \mu \mathrm{m})$ is smaller than that from MODIS $(1.2 \mu \mathrm{m})$, but larger than that from CERES $(0.5 \mu \mathrm{m})$. The response in $R_{\mathrm{e}}$ seen in AMIP exceeds anomalies suggested by CERES and MODIS throughout the drier period July to November and exhibits a largest decrease of $1.9 \mu \mathrm{m}$. However, the $R_{\mathrm{e}}$ anomalies from AMIP*, which are based on identical time periods as CERES and MODIS, agree fairly well with the satellite observations. Keeping in mind that the 1997 event was extraordinarily strong, the behaviour of $R_{\mathrm{e}}$ changes and consequently changes in the first indirect forcing given by our model seem to be reasonable.

\subsection{Quantifying the influence of rainfall}

Visual comparison of Fig. 3d with Fig. 10c and f suggests that changes responsible for the indirect forcing anomaly are spatially more strongly dependent on variations in rainfall patterns than seen for the direct forcing. To verify this, we calculated pattern correlations based on the difference between the AMIP and CLIM anomalies (AMIP anomaly minus CLIM anomaly) for the period July to November, within the region as shown in Fig. 3. Note that rainfall represents the AMIP rainfall anomaly only as rainfall rates are identical in CLIM's El Niño and La Niña simulations.

The strong spatial relationship between rainfall anomalies and the enhancement of radiative forcing is reflected by the pattern correlations presented in Table 5. Precipitation is most strongly correlated with $N_{\mathrm{d}}(r=-0.67)$; a slightly weaker correlation is found for sulphate aerosols $(r=-0.62)$, which is most likely a result of the positive correlation between rainfall and the liquid-water path $(r=0.44$; not included in Table 5). Increasing rainfall tends to be associated with more liquid-water clouds, and in-cloud oxidation of $\mathrm{SO}_{2}$ is the main source of $\mathrm{SO}_{4}$ in the model (Rotstayn and Lohmann, 2002). The impact of precipitation on OC burdens is weaker $(r=-0.49)$ as it covers both its hydrophobic and hydrophilic forms. We expect, however, that the correlation of rainfall with hydrophilic OC approximates the correlation to $\mathrm{SO}_{4}$ (although we do not have data to verify this). Taking sulphate aerosols as a surrogate for hydrophilic aerosols, the pattern correlations of $\mathrm{SO}_{4}$ with $N_{\mathrm{d}}$ and $R_{\mathrm{e}}(r=0.78$ and -0.67 , respectively) indicate that the spatial distribution of hydrophilic aerosols strongly influences the number of cloud droplets and corresponding droplet sizes. OC is a much weaker predictor ( 0.65 and -0.51 , respectively). As expected, the correlation between $N_{\mathrm{d}}$ and $R_{\mathrm{e}}$ is strong with $r=-0.69$, and so is the correlation between precipitation and $R_{\mathrm{e}}(r=-0.61)$.

The rainfall pattern correlates weakly with the aerosol optical depth $\left(\tau_{550}\right)(r=-0.28)$. The correlation is somewhat stronger for the small particle aerosol optical depth $\tau_{\mathrm{sp}}$ as it excludes dust and sea salt. As explained in Sect. 2.1, the latter is not treated prognostically in the model but is diagnosed solely as a function of wind speed, so it is not expected to correlate with rainfall.

The rather weak correlation of the rainfall anomaly with AODs ( $\tau_{550}$ and $\left.\tau_{\mathrm{sp}}\right)$ is probably caused by an increase of relative humidity associated with more cloud and higher rainfall 
Table 5. Pattern correlations describing the relationship between SST-induced changes (AMIP anomaly minus CLIM anomaly) representative for the period July to November and variables related to the direct and indirect radiative forcing. Included variables are the aerosol optical depth $\left(\tau_{550}\right)$ and small particle aerosol optical depth $\left(\tau_{\mathrm{sp}}\right)$ at $550 \mathrm{~nm}$, burdens of sulphate $\left(\mathrm{SO}_{4}\right)$ and organic carbonaceous aerosols (OC), cloud droplet number concentration $\left(N_{\mathrm{d}}\right)$ and precipitation (Prec).

\begin{tabular}{l|ccccccr}
\hline & $\tau_{550}$ & $\tau_{\mathrm{sp}}$ & $\mathrm{SO}_{4}$ & $\mathrm{OC}$ & $N_{\mathrm{d}}$ & $R_{\mathrm{e}}$ & Prec \\
\hline$\tau_{550}$ & 1.0 & 0.88 & 0.77 & 0.76 & 0.47 & -0.38 & -0.28 \\
$\tau_{\mathrm{sp}}$ & & 1.0 & 0.77 & 0.90 & 0.59 & -0.45 & -0.37 \\
$\mathrm{SO}_{4}$ & & & 1.0 & 0.79 & 0.78 & -0.67 & -0.62 \\
$\mathrm{OC}$ & & & & 1.0 & 0.65 & -0.51 & -0.49 \\
$N_{\mathrm{d}}$ & & & & & 1.0 & -0.69 & -0.67 \\
$R_{\mathrm{e}}$ & & & & & & 1.0 & 0.61 \\
Prec & & & & & & & 1.0 \\
\hline
\end{tabular}

rates. Increasing relative humidity tends to increase AODs and counteracts the AOD reduction due to rainfall-induced aerosol removal. Higher $\mathrm{SO}_{4}$ and $\mathrm{OC}$ burdens, however, correlate strongly with aerosol optical depths $(r=0.77$ and 0.76 for $\tau_{550}$, and 0.77 and 0.90 for $\tau_{\mathrm{sp}}$ ).

In summary, the rainfall anomalies exert a strong effect on indirect forcing via their influence on hydrophilic aerosols, which in turn affect $\mathrm{N}_{\mathrm{d}}$ and $\mathrm{R}_{\mathrm{e}}$. The effect on direct forcing is weaker, because increased rainfall is associated with increased relative humidity, which tends to increase AOD.

\subsection{Uncertainties and limitations}

Possibly the largest uncertainties in our study concern (1) emissions of SOA in the GFED3 inventory, and (2) biases in the ENSO-related rainfall anomaly in the model.

Secondary organic aerosols are not included in the GFED emission estimates; this is likely to contribute to the underestimate of AODs as seen in the comparison with observed AODs in El Niño and La Niña conditions (Fig. 7). An underestimate of AODs is likely to cause an underestimate of forcing anomalies.

An impact of opposite sign is expected to arise from the ENSO-related rainfall anomaly in the AMIP experiment. The rainfall anomaly is too strongly concentrated in a narrow band along the equator. This probably contributes to a modest overestimate of the AOD and radiative forcing anomalies in AMIP, as well as a bias in the spatial patterns (Sect. 3.2.1). The bias occurs mainly in the La Niña simulation, when aerosol emissions are low, and this will tend to reduce the effect of the rainfall bias. As discussed in Sect. 3.7, anomalies in the indirect aerosol effect in AMIP are strongly influenced by rainfall anomalies, so the indirect effect will be more affected than the direct effect.

Other uncertainties arise from the design of our model experiments and model parameterisations.
The experiments performed for this study are idealised, in the sense that we concentrated on the direct and indirect radiative impact that appears instantaneously due to the presence of aerosols. By design, feedbacks of the aerosol radiative effects on the meteorology are not treated (see Sect. 2.2 and appendix). This includes the influence on the atmospheric circulation due to surface cooling and atmospheric heating.

As SSTs used for the AMIP experiment are derived from observations (Hurrell et al., 2008), possible cooling effects on SSTs due to aerosol forcing (Rajeev et al., 2008) are in principle resolved by the AMIP simulations. Owing to the experimental set-up, however, circulation changes due to atmospheric heating caused by $\mathrm{BC}$ aerosols were not considered. These could involve stabilisation of the atmosphere (Fan et al., 2008) or locally increase vertical upward motion (Ott et al., 2010; Koch and Del Genio, 2010).

The impact of aerosols on precipitation is also disregarded in this study. There is evidence, however, that Indonesian biomass-burning aerosols suppress precipitation to some degree (Graf et al., 2009; Langmann, 2007). Thus a positive feedback on the increase of aerosols can possibly be expected.

As in many GCMs, the treatment of aerosols has some limitations. Carbonaceous aerosols are converted from their hydrophobic into a hydrophilic state via a fixed e-folding time instead of responding to varying conditions. We also assumed that the emissions of black and organic carbonaceous aerosols are hydrophilic with a specified fraction rather than being particle size-dependent. As noted in Sect. 2.1, we used prescribed oxidants using a monthly-mean average representative for the modern-day climate. The 1997 fires, however, impacted $\mathrm{OH}^{-}$and $\mathrm{O}_{3}$ levels, leading to changes of opposite signs (Duncan et al., 2003). Hence, our simplified treatment of oxidants in the sulphur cycle may lead to biased sulphate burdens.

Moreover, the response in cloud droplets and hence in the indirect radiative forcing presented here are likely to be sensitive to the particular scheme we used for the parametrization of cloud droplet number concentration. The cloud droplet number concentration in the stratiform-cloud scheme is determined as an empirical function of aerosol mass, which neglects much of the subtle physics and chemistry involved in cloud droplet nucleation (Lance et al., 2004).

\subsection{Key findings}

The key new findings in our study relate to (1) inclusion of indirect effects in our estimates of the radiative forcing of Indonesian BB aerosols, and (2) demonstration that the effects of ENSO-related meteorological changes are comparable to, or possibly larger than, the effects of changes in emissions.

Our results presented in the previous subsections showed that for both the direct and the indirect effects, radiative forcing is enhanced when ENSO-related rainfall and circulation 
Table 6. Direct radiative forcing from the El Niño and La Niña simulations of CLIM and AMIP averaged over the months July - November, as well as the direct and indirect radiative forcing anomaly. Direct and indirect forcing values (in $\mathrm{Wm}^{2}$ ) are presented for the surface (surf) and top of atmosphere (TOA) as regional average for the Indonesian region (Indon, $\left(5.6^{\circ} \mathrm{N}-11.2^{\circ} \mathrm{S}, 96.6^{\circ} \mathrm{E}-\right.$ $\left.150.9^{\circ} \mathrm{E}\right)$ ) and a extended region referred to as the Extended Indonesian region (ExtIndon, $\left(11.2^{\circ} \mathrm{N}-11.2^{\circ} \mathrm{S}, 60^{\circ} \mathrm{E}-160^{\circ} \mathrm{E}\right)$ ).

\begin{tabular}{c|c|cc|cc}
\hline & & \multicolumn{2}{|c}{ surf } & \multicolumn{2}{c}{ TOA } \\
& & Indon & ExtIndon & Indon & ExtIndon \\
\hline \multirow{3}{*}{ CLIM } & El Niño & -9.3 & -6.9 & -3.2 & -2.6 \\
& La Niña & -4.0 & -3.6 & -2.2 & -2.0 \\
& anomaly & -5.3 & -3.3 & -1.0 & -0.6 \\
\hline \multirow{3}{*}{ AMIP } & El Niño & -13.0 & -9.8 & -3.9 & -3.3 \\
& La Niña & -3.9 & -3.5 & -2.1 & -1.9 \\
& anomaly & -9.1 & -6.3 & -1.8 & -1.4 \\
\hline \multirow{2}{*}{ CLIM } & anomaly & -0.7 & -0.6 & -0.6 & -0.5 \\
\hline \multirow{2}{*}{ AMIP } & anomaly & -2.2 & -1.6 & -2.0 & -1.4 \\
\hline
\end{tabular}

anomalies are considered in simulating the distribution of Indonesian BB aerosols. The characteristics and strength of the ENSO-related impact, however, are different for the direct and indirect forcing. We elaborate on this using Table 6, which summarizes the direct and indirect forcing anomalies (El Niño minus La Niña) for the Indonesian region, averaged over the high-emission months July to November. The table also includes corresponding forcing values for an expanded region covering much of the Indian Ocean $\left(11.2^{\circ} \mathrm{N}-11.2^{\circ} \mathrm{S}\right.$, $60^{\circ} \mathrm{E}-160^{\circ} \mathrm{E}$ ), as well as the direct forcing estimates from the El Niño and La Niña simulations individually. Note that for the indirect forcing only the anomaly is physically meaningful (see the appendix); hence, indirect forcing estimates for the El Niño and La Niña simulations are not included in Table 6.

For the direct forcing, the effects of SST perturbations are comparable to the effects of emission changes, both at TOA and the surface. The difference between the direct radiative forcing anomalies in the Indonesian region from the AMIP experiment $\left(-9 \mathrm{Wm}^{-2}\right.$ at the surface and $-2 \mathrm{Wm}^{-2}$ at TOA) and corresponding values from CLIM $\left(-5 \mathrm{Wm}^{-2}\right.$ and $-1 \mathrm{Wm}^{-2}$, respectively) indicates an overall strengthening of the radiative impact of $4 \mathrm{Wm}^{-2}$ at the surface and $1 \mathrm{Wm}^{-2}$ at TOA in AMIP (see Table 6). Those values are of similar magnitude as the radiative forcing anomalies resulting from emission anomalies only (CLIM).

The impact of SSTs on the magnitude of the indirect radiative forcing exceeds the impact from emission changes. In the months July to November the indirect forcing anomaly in the Indonesian region is $-0.7 \mathrm{Wm}^{-2}$ at the surface and $-0.6 \mathrm{Wm}^{-2}$ at TOA in CLIM, whilst in AMIP estimates are respectively $-2.2 \mathrm{Wm}^{-2}$ and $-2.0 \mathrm{Wm}^{-2}$ (see Table 6). Thus, in our experiment the indirect forcing anomaly is approximately tripled when the meteorological changes associated with ENSO are considered.

Our results suggest that the different behaviour of direct and indirect effects is likely to arise from the impact of rainfall anomalies on hydrophilic aerosols (see Sect. 3.7). While the strengthening of the direct forcing is directly linked to the amounts of the sum of hydrophilic and hydrophobic aerosols, changes in the indirect forcing are solely dependent on changes in the amount of hydrophilic aerosols. Hence, as only hydrophilic aerosols are effectively removed from the atmosphere by rain, anomalies in rainfall are reflected more strongly in the indirect forcing.

Sections 3.4 and 3.5 indicated that the ENSO-related impact on the direct and indirect forcing was not limited to the source regions as aerosols got advected westwards (Sect. 3.2.2), spreading over much of the Indian Ocean. As the rainfall anomalies were also a larger-scale phenomena (Sect. 3.2.1), the stronger enhancement of the indirect forcing (relative to the direct forcing) is also evident over a much broader region (see ExtIndon in Table 6).

\section{Summary and conclusions}

There have been several attempts to estimate the direct radiative impact of Indonesian BB aerosols during El Niño events. Some studies, however, considered and some disregarded that aerosol transport and removal are changed during ENSO events due to altered atmospheric circulation patterns. It has been shown, however, that ENSO-related conditions considerably influence aerosol burdens (Heil et al., 2007), and hence possibly the radiative forcing from Indonesian BB aerosols. The present study investigates the effect of meteorological changes driven by ENSO-related SST anomalies on radiative forcing from Indonesian BB aerosols. We present for the first time estimates for the first indirect aerosol effect, and find that at TOA it is of comparable magnitude to the direct effect.

Two pairs of runs were performed using the CSIRO-Mk3.6 GCM, each pair consisting of an El Niño and a La Niña simulation. One experiment (CLIM) was driven by climatological SSTs, so that SSTs and hence meteorological conditions were identical in the El Niño and La Niña simulations. The other pair of runs (AMIP) were forced by realistic SSTs that included SST variations associated with ENSO so that atmospheric circulation patterns were different, corresponding to El Niño and La Niña conditions. In both CLIM and AMIP, the difference between the El Niño and the La Niña simulation gives radiative forcing anomalies that depend on the differing fire emission strengths of the years 1997 and 2000, 
respectively. Only in the case of AMIP, SST-induced meteorological changes are also considered.

We found that the magnitude and extent of the radiative perturbations are substantially changed due to the impact of ENSO-related SST anomalies, both for the direct and the first indirect aerosol effect. For the first indirect effect, the influence of SST-induced changes in rainfall and circulation exceeds that of changes in emissions. For the direct aerosol forcing, the influence of changes in SSTs and emissions are of comparable magnitude.

Averaged over the Indonesian region $\left(5.6^{\circ} \mathrm{N}-11.2^{\circ} \mathrm{S}\right.$, $96.6^{\circ} \mathrm{E}-150.9^{\circ} \mathrm{E}$ ) and for the months July to November, in which $\mathrm{BB}$ emissions were strongest, we computed a direct forcing anomaly of $-9 \mathrm{Wm}^{-2}$ at the surface and $-2 \mathrm{Wm}^{-2}$ at TOA in AMIP, while the estimated values in CLIM were smaller $\left(-5 \mathrm{Wm}^{-2}\right.$ and $-1 \mathrm{Wm}^{-2}$, respectively). The maximum difference between both experiments occurred in September, with a monthly average of $-9 \mathrm{Wm}^{-2}$ in CLIM and $-15 \mathrm{Wm}^{-2}$ in AMIP. Although somewhat smaller in magnitude, the amplification of the direct forcing anomalies is noticeable within a much broader area.

The stronger direct impact in AMIP is due to the coincidence of intense BB emissions during El Niño and an SSTinduced negative rainfall anomaly. Drier conditions favour an increase of aerosol burdens in the atmosphere due to reduced wet-scavenging, so that in the Indonesian region more aerosols accumulate. Simultaneously, a change in the wind patterns leads to more effective aerosol transport away from the source regions into the Indian Ocean. Radiative perturbations due to BB aerosols become amplified in both magnitude and extent, but due to the more effective aerosol transport the radiative forcing anomaly appears slightly weakened over some of the major emission regions.

The indirect forcing anomaly showed a similar overall strengthening due to the impact of ENSO-related SST variations. For the Indonesian region, the average (first) indirect forcing anomaly in the months July to November was $-0.7 \mathrm{Wm}^{-2}$ at the surface and $-0.6 \mathrm{Wm}^{-2}$ at TOA in CLIM, whilst in AMIP it was $-2.2 \mathrm{Wm}^{-2}$ and $-2.0 \mathrm{Wm}^{-2}$, respectively. The indirect forcing anomaly was strongest at the TOA in September with $-0.9 \mathrm{Wm}^{-2}$ in CLIM and $-2.4 \mathrm{Wm}^{-2}$ in AMIP. The response of cloud properties to altered meteorological conditions is different compared to the response of the direct forcing, and is not directly linked to the generally increased aerosol burdens and spatial distribution. Our results indicate a strong relationship between the pattern of rainfall changes and aerosol-induced changes of cloud properties. This can be attributed to the dependence of the number of cloud droplets and droplet sizes on the concentration of hydrophilic aerosols. As the latter are effectively washed out by rain, a decrease in rainfall has a positive feedback on the number of cloud droplets. This leads to smaller cloud droplet sizes, which consequently results in a stronger indirect aerosol effect. We compared modelled cloud droplet radii with values from satellite retrievals. The interpretation is difficult, as due to different reference wavelengths different cloud levels are sampled in the retrievals. However, based on the comparison presented here, we conclude that our estimates are reasonable.

As secondary organic aerosols associated with biomass burning are not considered in this study, our forcing anomalies are likely to be underestimated. This is in agreement with satellite-retrieved AODs from MISR and MODIS. On the other hand, the ENSO-related rainfall anomaly in the AMIP experiment is too strong along the equator, and this is likely to contribute to a modest overestimate of the forcing anomalies in AMIP, especially for the indirect effect. These limitations should be borne in mind when interpreting our specific results.

Subject to these caveats, we conclude that direct and indirect radiative perturbations from Indonesian BB emissions would be considerably underestimated if feedbacks of ENSO-related SST variations on radiative forcing are not taken into account. This might be of relevance for impact assessments, but also for the interpretation of other studies, as the most common method for estimating radiative forcing is based on climatological SSTs (Lohmann et al., 2010; Taylor et al., 2012). For Indonesian BB aerosols, this would not give an accurate answer for the radiative forcing.

More broadly, it is intriguing that climatic feedbacks due to variability in Indonesian BB aerosols may depend as strongly on the climatic state (rainfall and circulation) as on the emissions. For aerosols of this type, it is difficult to draw the line between "forcing" and "feedback". As discussed by Tosca et al. (2010), it is interesting to consider whether Indonesian BB aerosols influence El Niño dynamics on interannual or decadal time scales. This would require a fully coupled ocean-atmosphere GCM linked to a prognostic fire parameterization (e.g., Pechony and Shindell, 2009; Kloster et al., 2010). Our results suggest that accurate simulation of ENSO-related changes in circulation and rainfall is one requirement for complex modelling of this type to be successful.

\section{Appendix A}

The following gives a detailed description of the design of the double calls for estimating the direct and the indirect effect individually as used for both experiments CLIM and AMIP. Note that separate simulations were used for calculation of the direct and indirect forcing. In both cases it is the second call to the SW radiation scheme that affects the meteorology in the model.

In simulations for estimating the direct forcing, the indirect aerosol effect was switched off, and vice versa. For diagnosing the direct aerosol effect, both calls of the SW radiation scheme used a fixed value of cloud droplet number concentration $\left(\mathrm{N}_{\mathrm{d}}=100 \times 10^{6} \mathrm{~m}^{-3}\right)$, to ensure that the indirect aerosol effect was turned off. In the first call the radiation 
scheme "saw" the aerosols. In the second call (which affects the meteorology in the model), the direct effects of aerosols were set to zero. This implies that the meteorology remained unchanged by aerosol effects. As a result, the meteorology in the CLIM experiment is identical for the El Niño and La Niña runs.

In simulations used for calculation of the first indirect effect, direct aerosol effects were turned off by setting aerosols to zero for the direct aerosol effects in both calls to the SW scheme. The first call used $\mathrm{N}_{\mathrm{d}}$ from equation 1 and the second call used a fixed value $\left(\mathrm{N}_{\mathrm{d}}=100 \times 10^{6} \mathrm{~m}^{-3}\right)$. Hence, as for the direct aerosol effect, aerosols had no impact on the meteorology, so that the meteorology is identical for the El Niño and La Niña runs in the CLIM experiment.

Note that, for the indirect effect, the differences between the SW fluxes calculated from the first and second calls in each run (say, $\Delta \mathrm{F}_{1997}$ and $\Delta \mathrm{F}_{2000}$ ) are not physically meaningful, since the fixed value of $\mathrm{N}_{\mathrm{d}}$ in the second call is arbitrary. However, the difference of these between the El Niño and La Niña runs $\left(\Delta \mathrm{F}_{1997}-\Delta \mathrm{F}_{2000}\right)$ represents the indirect forcing between 1997 and 2000, due to cancellation of the fixed value of $\mathrm{N}_{\mathrm{d}}$. A similar method was used by Rotstayn et al. (2009) and Lohmann et al. (2010).

Acknowledgements. We are grateful to Melita Keywood and Mick Meyer for their thoughts and fruitful discussions on this topic and thank Stacey Dravitzki for proof-reading. This work was supported by the NCI National Facility at the ANU.

Edited by: Y. Balkanski

\section{References}

Adler, R. F., Huffman, G. J., Chang, A., Ferraro, R., Xie, P. P., Janowiak, J., Rudolf, B., Schneider, U., Curtis, S., Bolvin, D., Gruber, A., Susskind, J., Arkin, P., and Nelkin, E.: The version-2 global precipitation climatology project (GPCP) monthly precipitation analysis (1979present), J. Hydrometeorol., 4, 1147-1167, doi:10.1175/15257541(2003)004<1147:TVGPCP>2.0.CO;2, 2003.

Albrecht, B. A.: Aerosols, Cloud Microphysics, and Fractional Cloudiness, Science, NY, 245, 1227-1230, doi:10.1126/science.245.4923.1227, 1989.

Andreae, M. and Merlet, P.: Emission of trace gases and aerosols from biomass burning, Global Biogeochem. Cy., 15, 955-966, doi:10.1029/2000GB001382, 2001.

Chen, W.-T., Kahn, R. A., Nelson, D., Yau, K., and Seinfeld, J. H.: Sensitivity of multiangle imaging to the optical and microphysical properties of biomass burning aerosols, J. Geophys. Res., 113, D10203, doi:10.1029/2007jd009414, 2008.

Collier, J. C. and Bowman, K. P.: Diurnal cycle of tropical precipitation in a general circulation model, J. Geophys. Res., 109, D17105, doi:10.1029/2004jd004818, 2004.

Cooke, W. F., Liousse, C., Cachier, H., and Feichter, J.: Construction of a 1 degrees x 1 degrees fossil fuel emission data set for carbonaceous aerosol and implementation and radiative impact in the ECHAM4 model, J. Geophys. Res., 104, 22137-22162, doi:10.1029/1999jd900187, 1999.

Davison, P. S., Roberts, D. L., Arnold, R. T., and Colvile, R. N.: Estimating the direct radiative forcing due to haze from the 1997 forest fires in Indonesia, J. Geophys. Res., 109, D10207, doi:10.1029/2003jd004264, 2004.

Dentener, F., Kinne, S., Bond, T., Boucher, O., Cofala, J., Generoso, S., Ginoux, P., Gong, S., Hoelzemann, J. J., Ito, A., Marelli, L., Penner, J. E., Putaud, J. P., Textor, C., Schulz, M., van der Werf, G. R., and Wilson, J.: Emissions of primary aerosol and precursor gases in the years 2000 and 1750 prescribed data-sets for AeroCom, Atmos. Chem. Phys., 6, 4321-4344, doi:10.5194/acp-64321-2006, 2006.

Duncan, B. N., Bey, I., Chin, M., Mickley, L. J., Fairlie, T. D., Martin, R. V., and Matsueda, H.: Indonesian wildfires of 1997: Impact on tropospheric chemistry, J. Geophys. Res., 108, 4458, doi:10.1029/2002jd003195, 2003.

Fan, J., Zhang, R., Tao, W.-K., and Mohr, K. I.: Effects of aerosol optical properties on deep convective clouds and radiative forcing, J. Geophys. Res., 113, D08209, doi:10.1029/2007jd009257, 2008.

Feichter, J., Kjellström, E., Rodhe, H., Dentener, F., Lelieveldi, J., and Roelofs, G.-J.: Simulation of the tropospheric sulfur cycle in a global climate model, Atmos. Environ., 30, 1693-1707, doi:10.1016/1352-2310(95)00394-0, 1996.

Giglio, L., Randerson, J. T., van der Werf, G. R., Kasibhatla, P. S., Collatz, G. J., Morton, D. C., and DeFries, R. S.: Assessing variability and long-term trends in burned area by merging multiple satellite fire products, Biogeosciences, 7, 1171-1186, doi:10.5194/bg-7-1171-2010, 2010.

Ginoux, P., Chin, M., Tegen, I., Prospero, J. M., Holben, B., Dubovik, O., and Lin, S. J.: Sources and distributions of dust aerosols simulated with the GOCART model, J. Geophys. Res., 106, 20255-20273, doi:10.1029/2000jd000053, 2001.

Gordon, H. B., O'Farrell, S. P., Collier, M. A., Dix, M. R., Rotstayn, L. D., Kowalczyk, E. A., Hirst, A. C., and Watterson, I. G.: The CSIRO Mk3.5 Climate Model, Technical Report No. 21, The Centre for Australian Weather and Climate Research, Aspendale, Vic., Australia, 62 pp., available online at http://www.cawcr.gov. au/publications/technicalreports.php, 2010.

Graf, H. F., Yang, J., and Wagner, T. M.: Aerosol effects on clouds and precipitation during the 1997 smoke episode in Indonesia, Atmos. Chem. Phys., 9, 743-756, doi:10.5194/acp-9-743-2009, 2009.

Gregory, D. and Rowntree, P. R.: A mass flux convection scheme with representation of cloud ensemble characteristics and stability-dependent closure, Mon. Weather Rev., 118, 1483-1506, doi:10.1175/15200493(1990)118<1483:AMFCSW>2.0.CO;2, 1990.

Grieshop, A. P., Logue, J. M., Donahue, N. M., and Robinson, A. L.: Laboratory investigation of photochemical oxidation of organic aerosol from wood fires 1: measurement and simulation of organic aerosol evolution, Atmos. Chem. Phys., 9, 1263-1277, doi:10.5194/acp-9-1263-2009, 2009.

Heil, A., Langmann, B., and Aldrian, E.: Indonesian peat and vegetation fire emissions: study on factors influencing largescale smoke haze pollution using a regional atmospheric chemistry model, Mitig. Adapt. Strat. Global Change, 12, 113-133, doi:10.1007/s11027-006-9045-6, 2007. 
Hendon, H. H.: Indonesian rainfall variability: Impacts of ENSO and local air-sea interaction, J. Clim., 16, 1775-1790, doi:10.1175/1520-0442(2003)016<1775:irvioe > 2.0.CO;2, 2003.

Holtslag, A. A. M. and Boville, B. A.: Local versus nonlocal boundary-layer diffusion in a global climate model, J. Clim., 6, 1825-1842, doi:10.1175/15200442(1993)006<1825:LVNBLD>2.0.CO;2, 1993.

Huffman, G. J., Adler, R. F., Bolvin, D. T., and Gu, G.: Improving the global precipitation record: GPCP Version 2.1, Geophys. Res. Lett., 36, L17808, doi:10.1029/2009gl040000, 2009.

Hurrell, J. W., Hack, J. J., Shea, D., Caron, J. M., and Rosinski, J.: A new sea surface temperature and sea ice boundary dataset for the Community Atmosphere Model, J. Clim., 21, 5145-5153, doi:10.1175/2008jcli2292.1, 2008.

Iinuma, Y., Boge, O., Grafe, R., and Herrmann, H.: MethylNitrocatechols: Atmospheric Tracer Compounds for Biomass Burning Secondary Organic Aerosols, Envir. Sci. Technol., 44, 8453-8459, doi:10.1021/es102938a, 2010.

Jones, A., Roberts, D. L., and Slingo, A.: A climate model study of indirect radiative forcing by anthropogenic sulphate aerosols, Nature, 370, 450-453, doi:10.1038/370450a0, 1994.

Kahn, R. A., Gaitley, B. J., Martonchik, J. V., Diner, D. J., Crean, K. A., and Holben, B.: Multiangle Imaging Spectroradiometer (MISR) global aerosol optical depth validation based on 2 years of coincident Aerosol Robotic Network (AERONET) observations, J. Geophys. Res., 110, D10S04, doi:10.1029/2004jd004706, 2005.

Keywood, M. D., Ayers, G. P., Gras, J. L., Boers, R., and Leong, C. P.: Haze in the Klang Valley of Malaysia, Atmos. Chem. Phys., 3, 591-605, doi:10.5194/acp-3-591-2003, 2003.

King, M. D., Menzel, W. P., Kaufman, Y. J., Tanre, D., Gao, B. C., Platnick, S., Ackerman, S. A., Remer, L. A., Pincus, R., and Hubanks, P. A.: Cloud and aerosol properties, precipitable water, and profiles of temperature and water vapor from MODIS, IEEE Trans. Geosci. Remote Sens., 41, 442-458, doi:10.1109/tgrs.2002.808226, 2003.

Kitoh, A. and Arakawa, O.: On overestimation of tropical precipitation by an atmospheric GCM with prescribed SST, Geophys. Res. Lett., 26, 2965-2968, doi:10.1029/1999g1900616, 1999.

Kloster, S., Mahowald, N. M., Randerson, J. T., Thornton, P. E., Hoffman, F. M., Levis, S., Lawrence, P. J., Feddema, J. J., Oleson, K. W., and Lawrence, D. M.: Fire dynamics during the 20th century simulated by the Community Land Model, Biogeosciences, 7, 1877-1902, doi:10.5194/bg-7-1877-2010, 2010.

Koch, D. and Del Genio, A. D.: Black carbon semi-direct effects on cloud cover: review and synthesis, Atmos. Chem. Phys., 10, 7685-7696, doi:10.5194/acp-10-7685-2010, 2010.

Lamarque, J. F., Bond, T. C., Eyring, V., Granier, C., Heil, A., Klimont, Z., Lee, D., Liousse, C., Mieville, A., Owen, B., Schultz, M. G., Shindell, D., Smith, S. J., Stehfest, E., Van Aardenne, J., Cooper, O. R., Kainuma, M., Mahowald, N., McConnell, J. R., Naik, V., Riahi, K., and van Vuuren, D. P.: Historical (1850-2000) gridded anthropogenic and biomass burning emissions of reactive gases and aerosols: methodology and application, Atmos. Chem. Phys., 10, 7017-7039, doi:10.5194/acp10-7017-2010, 2010.

Lance, S., Nenes, A., and Rissman, T. A.: Chemical and dynamical effects on cloud droplet number: Implications for es- timates of the aerosol indirect effect, J. Geophys. Res., 109, doi:10.1029/2004jd004596, 2004.

Langmann, B.: A model study of smoke-haze influence on clouds and warm precipitation formation in Indonesia 1997/1998, Atmos. Environ., 41, 6838-6852, doi:10.1016/j.atmosenv.2007.04.050, 2007.

Levine, J. S.: The 1997 fires in Kalimantan and Sumatra, Indonesia: Gaseous and particulate emissions, Geophys. Res. Lett., 26, 815818, doi:10.1029/1999GL900067, 1999.

Liew, S. C., Lim, O. K., Kwoh, L. K., and Lim, H.: A study of the 1997 forest fires in South East Asia using SPOT quicklook mosaics, Igarss '98 - 1998 International Geoscience and Remote Sensing Symposium, Proceedings Vols 1-5: Sensing and Managing the Environment, Ieee, New York, USA, 1998.

Liu, Y., Daum, P. H., Guo, H., and Peng, Y.: Dispersion bias, dispersion effect, and the aerosol-cloud conundrum, Environ. Res. Lett., 3, 045021, doi:10.1088/1748-9326/3/4/045021, 2008.

Lohmann, U. and Feichter, J.: Global indirect aerosol effects: a review, Atmos. Chem. Phys., 5, 715-737, doi:10.5194/acp-5-7152005, 2005.

Lohmann, U., Feichter, J., Chuang, C. C., and Penner, J. E.: Prediction of the number of cloud droplets in the ECHAM GCM, J. Geophys. Res., 104, 24557-24563, doi:10.1029/1999jd900840, 1999.

Lohmann, U., Rotstayn, L., Storelvmo, T., Jones, A., Menon, S., Quaas, J., Ekman, A. M. L., Koch, D., and Ruedy, R.: Total aerosol effect: radiative forcing or radiative flux perturbation?, Atmos. Chem. Phys., 10, 3235-3246, doi:10.5194/acp-10-32352010, 2010.

Louis, J. F.: A parametric model of vertical eddy fluxes in the atmosphere, Bound.-Lay. Meteorol., 17, 187-202, doi:10.1007/bf00117978, 1979.

Martin, E. R. and Schumacher, C.: The Relationship between Tropical Warm Pool Precipitation, Sea Surface Temperature, and Large-Scale Vertical Motion in IPCC AR4 Models, J. Atmos. Sci., 69, 185-194, doi:10.1175/jas-d-11-0104.1, 2012.

McGregor, J. L.: Economical Determination of Departure Points for Semi-Lagrangian Models, Mon. Weather Rev., 121, 221-230, doi:10.1175/1520-0493(1993)121<0221:edodpf > 2.0.CO;2, 1993.

Menon, S. and Rotstayn, L.: The radiative influence of aerosol effects on liquid-phase cumulus and stratiform clouds based on sensitivity studies with two climate models, Clim. Dynam., 27, 345-356, doi:10.1007/s00382-006-0139-3, 2006.

Minnis, P., Sun-Mack, S., Chen, Y., Khaiyer, M. M., Yi, Y., Ayers, J. K., Brown, R. R., Dong, X., Gibson, S. C., Heck, P. W., Lin, B., Nordeen, M. L., Nguyen, L., Palikonda, R., Smith, W. L., Spangenberg, D. A., Trepte, Q. Z., and Xi, B.: CERES Edition2 Cloud Property Retrievals Using TRMM VIRS and Terra and Aqua MODIS Data - Part II: Examples of Average Results and Comparisons With Other Data, IEEE Trans. Geosci. Remote Sens., 1-30, doi:10.1109/TGRS.2011.2144602, 2011.

Murdiyarso, D. and Adiningsih, E. S.: Climate anomalies, Indonesian vegetation fires and terrestrial carbon emissions, Mitig. Adapt. Strat. Global Change, 12, 101-112, doi:10.1007/s11027006-9047-4, 2007.

Neale, R. and Slingo, J.: The maritime continent and its role in the global climate: A GCM study, J. Clim., 16, 834-848, doi:10.1175/1520-0442(2003)016<0834:TMCAIR > 2.0.CO;2, 
2003.

O'Dowd, C. D., Smith, M. H., Consterdine, I. E., and Lowe, J. A.: Marine aerosol, sea-salt, and the marine sulphur cycle: A short review, Atmos. Environ., 31, 73-80, doi:10.1016/S13522310(96)00106-9, 1997.

Ott, L., Duncan, B., Pawson, S., Colarco, P., Chin, M., Randles, C., Diehl, T., and Nielsen, E.: Influence of the 2006 Indonesian biomass burning aerosols on tropical dynamics studied with the GEOS-5 AGCM, J. Geophys. Res., 115, D14121, doi:10.1029/2009jd013181, 2010.

Page, S. E., Siegert, F., Rieley, J. O., Boehm, H. D. V., Jaya, A., and Limin, S.: The amount of carbon released from peat and forest fires in Indonesia during 1997, Nature, 420, 61-65, doi:10.1038/nature01131, 2002.

Parameswaran, K., Nair, S. K., and Rajeev, K.: Impact of Indonesian forest fires during the $1997 \mathrm{El} \mathrm{Nino} \mathrm{on} \mathrm{the} \mathrm{aerosol} \mathrm{distri-}$ bution over the Indian Ocean, Adv. Space. Res., 33, 1098-1103, doi:10.1016/S0273-1177(03)00736-1, 2004.

Pechony, O. and Shindell, D. T.: Fire parameterization on a global scale, J. Geophys. Res., 114, D16115, doi:10.1029/2009jd011927, 2009.

Pincus, R. and Baker, M. B.: Effect of Precipitation on the Albedo Susceptibility of Clouds in the Marine Boundary-Layer, Nature, 372, 250-252, doi:10.1038/372250a0, 1994.

Platnick, S.: Vertical photon transport in cloud remote sensing problems, J. Geophys. Res., 105, 22919-22935, doi:10.1029/2000jd900333, 2000.

Podgorny, I. A., Li, F., and Ramanathan, V.: Large aerosol radiative forcing due to the 1997 Indonesian forest fire, Geophys. Res. Lett., 30, 1028, doi:10.1029/2002g1015979, 2003.

Rajeev, K., Parameswaran, K., Nair, S. K., and Meenu, S.: Observational evidence for the radiative impact of Indonesian smoke in modulating the sea surface temperature of the equatorial Indian Ocean, J. Geophys. Res., 113, D17201, doi:10.1029/2007jd009611, 2008.

Ramanathan, V.: Aerosols, Climate, and the Hydrological Cycle, Science, NY, USA, 294, 2119-2124, doi:10.1126/science.1064034, 2001.

Remer, L. A., Kaufman, Y. J., Tanre, D., Mattoo, S., Chu, D. A., Martins, J. V., Li, R. R., Ichoku, C., Levy, R. C., Kleidman, R. G., Eck, T. F., Vermote, E., and Holben, B. N.: The MODIS aerosol algorithm, products, and validation, J. Atmos. Sci., 62, 947-973, doi:10.1175/jas3385.1, 2005.

Rotstayn, L. D.: A physically based scheme for the treatment of stratiform clouds and precipitation in large-scale models. I: Description and evaluation of the microphysical processes, Q. J. Roy. Meteorol. Soc., 123, 1227-1282, doi:10.1002/qj.49712354106, 1997.

Rotstayn, L. D. and Liu, Y. G.: Sensitivity of the first indirect aerosol effect to an increase of cloud droplet spectral dispersion with droplet number concentration, J. Clim., 16, 3476-3481, doi:10.1175/1520-0442(2003)016<3476:SOTFIA > 2.0.CO;2, 2003.

Rotstayn, L. D. and Liu, Y. G.: A smaller global estimate of the second indirect aerosol effect, Geophys. Res. Lett., 32, L05708, doi:10.1029/2004g1021922, 2005.

Rotstayn, L. D. and Lohmann, U.: Simulation of the tropospheric sulfur cycle in a global model with a physically based cloud scheme, J. Geophys. Res., 107, 4592, doi:10.1029/2002jd002128, 2002.

Rotstayn, L. D., Cai, W. J., Dix, M. R., Farquhar, G. D., Feng, Y., Ginoux, P., Herzog, M., Ito, A., Penner, J. E., Roderick, M. L., and Wang, M. H.: Have Australian rainfall and cloudiness increased due to the remote effects of Asian anthropogenic aerosols?, J. Geophys. Res., 112, D09202, doi:10.1029/2006jd007712, 2007.

Rotstayn, L. D., Keywood, M. D., Forgan, B. W., Gabric, A. J., Galbally, I. E., Gras, J. L., Luhar, A. K., McTainsh, G. H., Mitchell, R. M., and Young, S. A.: Possible impacts of anthropogenic and natural aerosols on Australian climate: a review, Int. J. Climatol., 29, 461-479, doi:10.1002/joc.1729, 2009.

Rotstayn, L. D., Collier, M. A., Mitchell, R. M., Qin, Y., Campbell, S. K., and Dravitzki, S. M.: Simulated enhancement of ENSOrelated rainfall variability due to Australian dust, Atmos. Chem. Phys., 11, 6575-6592, doi:10.5194/acp-11-6575-2011, 2011.

Rotstayn, L. D., Jeffrey, S. J., Collier, M. A., Dravitzki, S. M., Hirst, A. C., Syktus, J. I., and Wong, K. K.: Aerosol- and greenhouse gas-induced changes in summer rainfall and circulation in the Australasian region: a study using single-forcing climate simulations, Atmos. Chem. Phys., 12, 6377-6404, doi:10.5194/acp-126377-2012, 2012.

Saji, N. H., Goswami, B. N., Vinayachandran, P. N., and Yamagata, T.: A dipole mode in the tropical Indian Ocean, Nature, 401, 360363, doi:10.1038/43855, 1999.

Suzuki, K., Nakajima, T. Y., and Stephens, G. L.: Particle Growth and Drop Collection Efficiency of Warm Clouds as Inferred from Joint CloudSat and MODIS Observations, J. Atmos. Sci., 67, 3019-3032, doi:10.1175/2010jas3463.1, 2010.

Taylor, K. E., Stouffer, R. J., and Meehl, G. A.: An Overview of CMIP5 and the Experiment Design, B. Am. Meteorol. Soc., doi:10.1175/BAMS-D-11-00094.1, 2012.

Tosca, M. G., Randerson, J. T., Zender, C. S., Flanner, M. G., and Rasch, P. J.: Do biomass burning aerosols intensify drought in equatorial Asia during El Nino?, Atmos. Chem. Phys., 10, 35153528, doi:10.5194/acp-10-3515-2010, 2010.

Twomey, S.: Pollution and the planetary albedo, Atmos. Environ., 8, 1251-1256, doi:10.1016/0004-6981(74)90004-3, 1974.

van der Werf, G. R., Randerson, J. T., Giglio, L., Collatz, G. J., Mu, M., Kasibhatla, P. S., Morton, D. C., DeFries, R. S., Jin, Y., and van Leeuwen, T. T.: Global fire emissions and the contribution of deforestation, savanna, forest, agricultural, and peat fires (19972009), Atmos. Chem. Phys., 10, 11707-11735, doi:10.5194/acp10-11707-2010, 2010.

Van Leer, B.: Towards the ultimate conservative difference scheme. IV. A new approach to numerical convection, J. Comput. Phys., 23, 276-299, doi:10.1016/0021-9991(77)90095-x, 1977.

Webster, P. J., Moore, A. M., Loschnigg, J. P., and Leben, R. R.: Coupled ocean-atmosphere dynamics in the Indian Ocean during 1997-98, Nature, 401, 356-360, doi:10.1038/43848, 1999.

Wielicki, B. A., Barkstrom, B. R., Harrison, E. F., Lee, R. B., Louis Smith, G., and Cooper, J. E.: Clouds and the Earth's Radiant Energy System (CERES): An Earth Observing System Experiment, Bull. Am. Meteorol. Soc., 77, 853868, doi:10.1175/1520-0477(1996)077<0853:catere>2.0.CO;2, 1996.

Wood, R.: Cancellation of aerosol indirect effects in marine stratocumulus through cloud thinning, J. Atmospheric Sci., 64, 2657-2669, doi:10.1175/jas3942.1, 2007. 
Wooster, M. J., Perry, G. L. W., and Zoumas, A.: Fire, drought and El Nino relationships on Borneo (Southeast Asia) in the pre-MODIS era (1980-2000), Biogeosciences, 9, 317-340, doi:10.5194/bg-9-317-2012, 2012.

Wu, R., Kirtman, B. P., and Pegion, K.: Local air-sea relationship in observations and model simulations, J. Clim., 19, 4914-4932, doi:10.1175/jcli3904.1, 2006.

Xie, P. and Arkin, P. A.: Global precipitation: a 17-year monthly analysis based on gauge observations, satellite estimates, and numerical model outputs, B. Am. Meteorol. Soc., 78, 2539-2558, 1997.
Yang, G. Y. and Slingo, J.: The diurnal cycle in the Tropics, Mon. Weather Rev., 129, 784-801, doi:10.1175/15200493(2001)129<0784:tdcitt>2.0.CO;2, 2001.

Zhang, S., Penner, J. E., and Torres, O.: Inverse modeling of biomass burning emissions using Total Ozone Mapping Spectrometer aerosol index for 1997, J. Geophys. Res., 110, D21306, doi:10.1029/2004JD005738, 2005. 